\title{
PIV Measurements of a Low-Noise Top-Mounted Propulsion Installation for a Supersonic Airliner
}

\author{
JAMES BRIDGES \& MARK P WERNET \\ NASA Glenn Research Center, Cleveland, OH 44135
}

\begin{abstract}
A model-scale exhaust system was tested to validate low-noise propulsion concepts and noise prediction methods. The tests, referred to as the Top-Mounted Propulsion 2017 (TMP17) tests, involved far-field acoustics, phased array, and particle image velocimetry (PIV). This paper covers the particle image velocimetry portion. Data were acquired at NASA Glenn's Aero-Acoustic Propulsion Lab for a series of nozzles with different chevron designs, both uninstalled and installed on a representative aircraft planform. The impact of the various chevron treatments on the turbulent velocity field was documented, along with the impact of the pylon and planform. When correlated with far-field acoustic measurements and phased array measurements, reported in companion papers, the explanation of acoustic benefits from top-mounted propulsion is clear, as is the path toward optimization of the concept.
\end{abstract}

\section{Nomenclature}

$\begin{array}{ll}c & \text { speed of sound } \\ I V P & \text { Inverted Velocity Profile } \\ M & \text { Mach number } \\ N P R & \text { nozzle total pressure ratio } \\ N T R & \text { nozzle total temperature ratio } \\ T & \text { temperature } \\ T K E & \text { turbulent kinetic energy } \\ \text { TMP17 } & \text { Top-Mounted Propulsion test 2017 } \\ u, v, w & \text { jet velocity components } \\ U & =\langle u\rangle \\ x & \text { axial coordinate } \\ \text { Subscripts } \\ p, f & \text { primary, fan streams } \\ j & \text { jet exit } \\ \text { mix } & \text { fully mixed } \\ \infty & \text { ambient } \\ \text { Other } & \\ \langle\bullet\rangle & \text { average of } \bullet\end{array}$

\section{Introduction}

In previous testing ${ }^{1}$, greater acoustic benefit was found from installation than any other technology for a given engine. A propulsion system mounted on the top of the aircraft had substantial (2-3EPNdB) shielding of jet mixing noise in the frequency range of peak human annoyance. Generically speaking, a propulsion system mounted under the aircraft body experienced substantial increase (again 2-3EPNdB) in the mixing noise due to reflection of this noise from the underside of the aircraft. Additionally, fan noise can be greatly reduced by having the propulsion inlet shielded from the ground by the aircraft planform. The results of system-level studies have been promising, with significant reduction of the jet mixing noise and removal of fan noise as a contributor to certification noise levels. The

\footnotetext{
$\dagger$ Acoustics Branch; AIAA Associate Fellow

$¥$ Optics and Photonics Branch; AIAA Associate Fellow
} 
aerodynamic penalties for top-mounted propulsion are still significant, hence every effort must be made to maximize the noise benefits of this installation.

The noise-modifying characteristics of chevrons and other mixing enhancement devices are fairly well-known ${ }^{2,3}$. These increase turbulent mixing near the nozzle, reducing the jet velocity and turbulence downstream. This has been used to reduce the peak, low-frequency jet noise directed at aft angles. However, the enhanced mixing increases the turbulent mixing energy close to the nozzle, which increases the high frequency noise at peak annoyance to humans. Balancing the benefit of reducing the low and enhancing the high frequencies to minimize human annoyance has been the challenge of designing such nozzles. Given that enhanced mixing usually decreases thrust ${ }^{4}$ further adds to the difficulty.

Installation changes the design rules for optimizing chevrons. When the enhanced-mixing nozzle is mounted on the top of the vehicle, the enhanced high frequencies can be shielded from the observer while the uncovered low frequencies downstream will be reduced. The result is a strong reduction in annoyance to the observer, if the mixing is brought far enough upstream and the noise adequately shielded. The key is accurately predicting the distribution of noise sources at different frequencies to produce the maximum benefit, while maintaining adequate aero thrust performance of the nozzle.

To explore this concept, a simplified acoustic analogy code for predicting jet noise was employed on an exhaust system studied previously with conventional, underbody installation ${ }^{1,5}$. The previous concept aircraft was reimagined with all top-mounted propulsion as shown in Figure 1. Chevron nozzles were designed that shifted the noise sources upstream to obtain greater suppression than the unenhanced, baseline nozzle. The previously tested inverted velocity profile (IVP) exhaust system, featuring a tertiary stream over a $180^{\circ}$ annulus, was used as the baseline nozzle. Chevrons were designed to augment mixing between the primary and flight streams, between the primary and tertiary streams, and between the tertiary and flight streams. A planform representation of the airframe was created to mimic the installation of the propulsion units on the top of the vehicle. Combinations of the nozzle, chevrons, and planform allowed evaluation of system-level estimates of noise reduction for the installation of the baseline nozzle, and exploration of the additional benefits of modifying noise source distributions.

The tests were also planned with validation of jet flow and noise prediction methods in mind. Modern jet noise prediction methods require that the turbulent plume of the jet be properly predicted as a precursor to the prediction of its sound. Therefore, a significant portion of the test was measurement of the plume's turbulent velocities using particle image velocimetry (PIV). Significant findings of this effort are presented in this paper. Measurements of the far-field sound $^{6}$ and of noise source distributions ${ }^{7}$ and predictions of the flow and noise of these configurations from ReynoldsAveraged Navier-Stokes simulations ${ }^{8}$ are also reported in this conference.

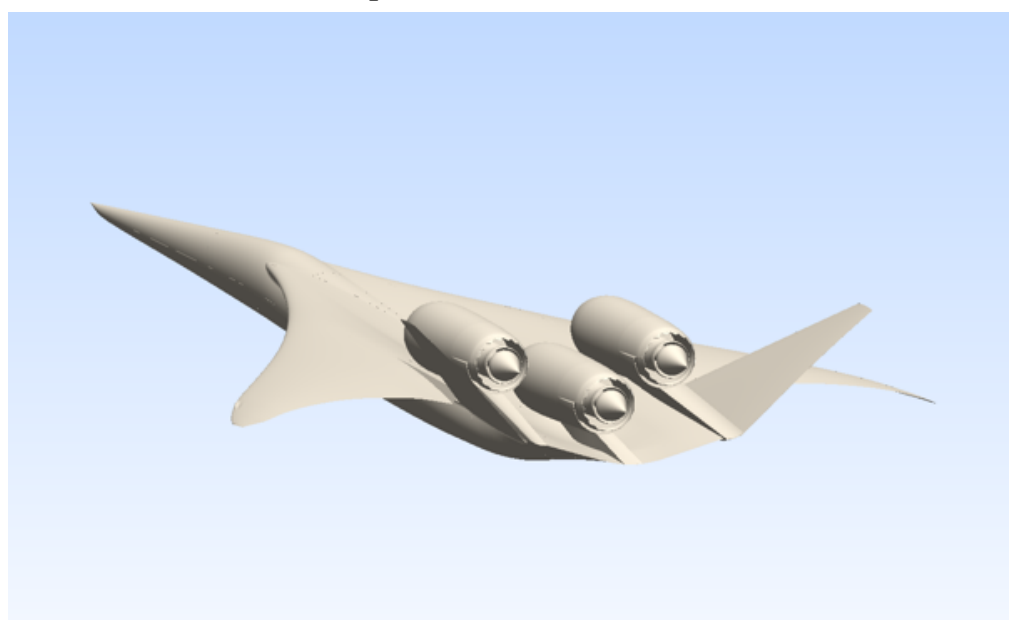

Figure 1. Concept aircraft with three top-mounted, podded engines.

\section{Facility and Instrumentation}

The test was conducted in the NASA Glenn Research Center Aero-Acoustic Propulsion Laboratory (AAPL). The AAPL is a 20m-radius anechoic geodesic hemispherical dome. Acoustic wedges cover the walls of the dome and approximately half of the floor area. The Nozzle Aeroacoustic Test Rig (NATR) was contained in the AAPL. The NATR provided the flight stream for the jet rig. The NATR ductwork consisted of an annular ejector system connected 
to a plenum followed by the transition section which was an ASME long-radius, low-beta venturi nozzle. This flow was exhausted through a $1.35 \mathrm{~m}$-diameter nozzle to form a free jet to provide a simulated flight stream around the test article. The centerline of the free jet was $3 \mathrm{~m}$ above the floor.

The High Flow Jet Exit Rig (HFJER), located at the downstream end of the NATR, is the structure through which heated air was delivered from the facility compressed air system to the test article. The HFJER is effectively a turbofan engine simulator. The first air stream was heated using a natural gas combustor. The second air stream was heated using a heat exchanger. For this test, the HFJER was fitted with a third annular stream of air to feed three-stream, variable cycle nozzles. This third stream, which was diverted from the usual second stream prior to its control valve, was independently controlled for pressure but had roughly the same temperature as the second stream.

The components of the jet rig and model system are shown in Figure 2.

The rig was fitted with a rotating collar section downstream of the third-stream plenum. A support arm cantilevered downstream from the outer rotating spool of the rotating collar section to support the model planforms on the nozzle and allow them to be positioned at multiple azimuthal angles. Next on the stack was a stream inverter that ducted the second annular airstream into the center of the nozzle system, producing the inverted velocity profile (IVP) capability. The nozzle model hardware, described below in detail, attached to this stream invertor. Rotations of the model system, both nozzle and planform, were dictated by optical access of the PIV system.

The rig was instrumented to record total temperature and total pressure at the charging station on all streams, including the IVP-specific instrumentation in the cold stream of the inner flow path. In addition, mass flowrates were recorded using flow venturi. Ambient conditions were recorded on the facility computer, along with all rig instrumentation, at a $1 \mathrm{~Hz}$ sample rate during periods of acoustic data acquisition. Ambient pressure was recorded in a sheltered location within the dome.

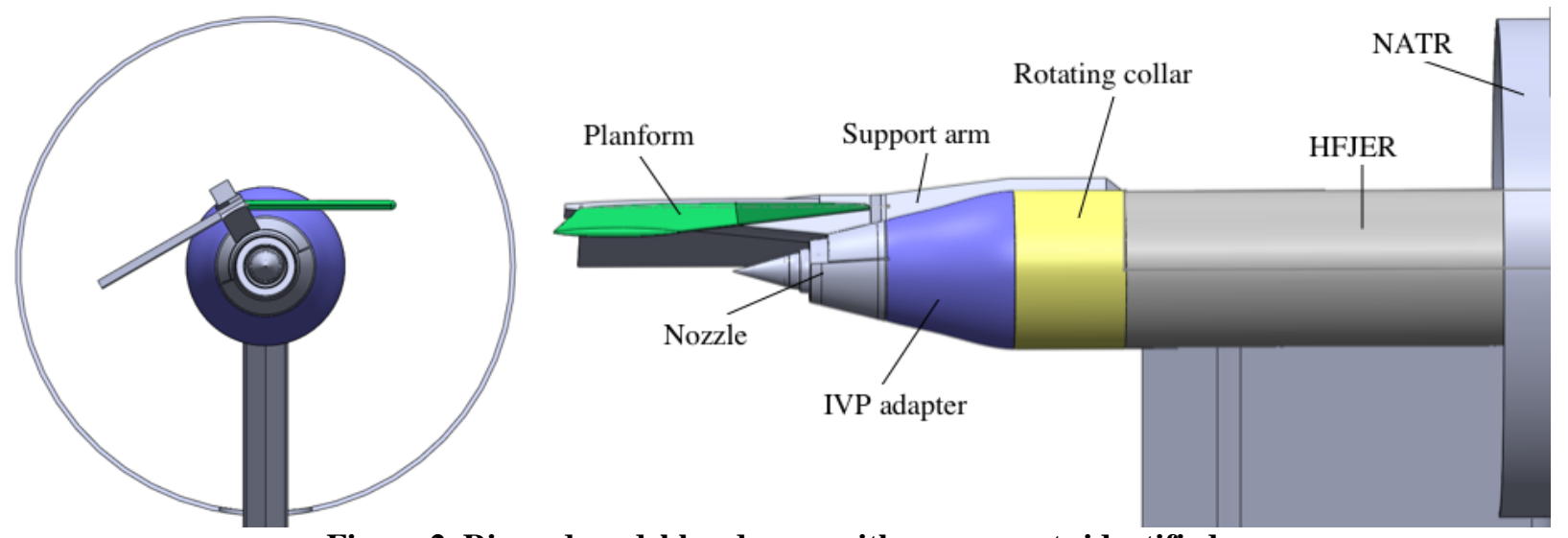

Figure 2. Rig and model hardware, with components identified.

\section{A. Particle Image Velocimetry}

Mean and turbulence velocity measurements were made using particle image velocimetry (PIV). In this test entry, only cross-stream three-component PIV measurements were made (no streamwise planes). Figure 3 shows a representation of the PIV equipment in the cross-stream optical orientation.

The PIV laser light sheet was provided by a $400 \mathrm{~mJ}$ per pulse, $532 \mathrm{~nm}$, dual-head Nd-YAG laser with the vertical laser sheet fanning from optics below the jet centerline. A stereo pair of $2.6 \mathrm{~K} \mathrm{x} 4 \mathrm{~K}$ pixel CCD cameras were mounted downstream from the nozzle exit on a large traverse system at approximately $\pm 37^{\circ}$ off the jet centerline in the horizontal plane. The cameras were equipped with $185 \mathrm{~mm}$ lenses, $8 \mathrm{~mm}$ extension tubes and daylight filters, since the NATR is an outdoor facility operated during daylight hours. When the PIV stereo vector fields are combined, the field-of-view for the reconstructed three-component velocity field was 420 by $365 \mathrm{~mm}$. 


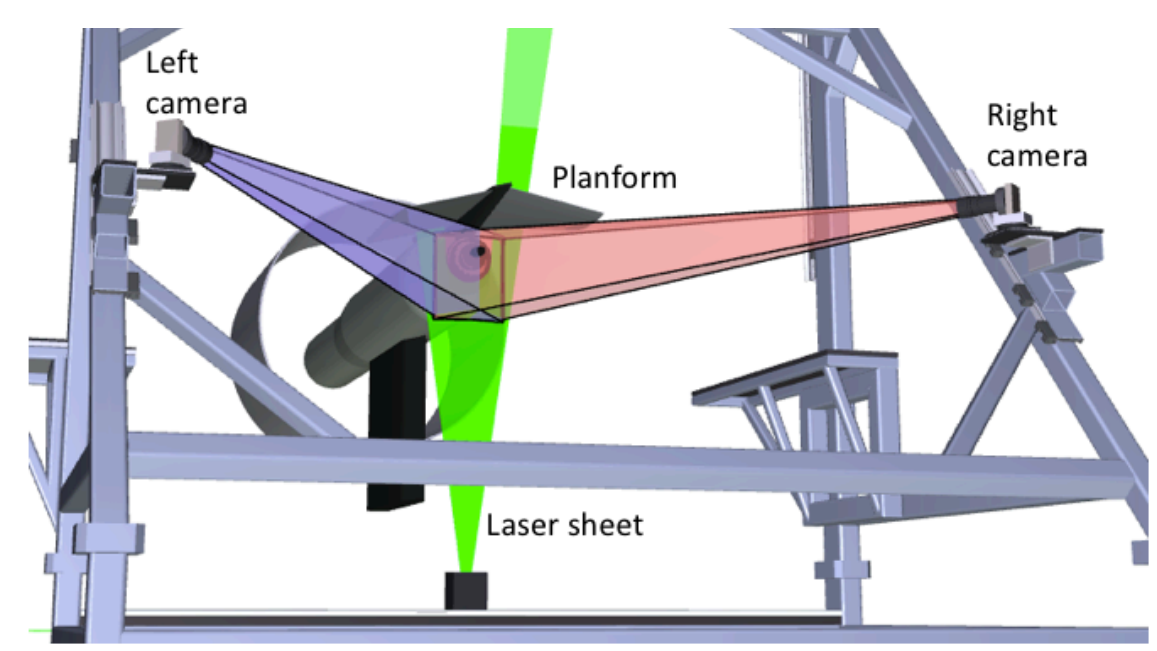

Figure 3. PIV setup for acquisition of flow velocities in cross-stream planes.

Twelve axial stations were acquired for all model configurations at the locations given in Table 1. The first three stations were upstream of the plug tip, and the first six planes were upstream of the planform trailing edge for the installed configurations. The light sheet was partially blocked by the plug for the first three stations; most uninstalled configurations were measured twice, with the nozzle rotated to two different angles, to capture the full flow around the plug. For the installed configurations, laser flare from the underside of the planform was minimized by placing the cameras as close to grazing view of the surface as possible while keeping the laser impact line hidden from the cameras. This precluded obtaining data near the planform surface for the most upstream stations. Some data was lost near the plug by the laser flare off the underside of the plug.

Table 1 Axial stations for flow acquisition. Axial location relative to primary nozzle exit plane.

$\begin{array}{cc}\text { index } & x(\mathrm{~mm}) \\ 1 & 5 \\ 2 & 70 \\ 3 & 150 \\ 4 & 250 \\ 5 & 350 \\ 6 & 500 \\ 7 & 650 \\ 8 & 850 \\ 9 & 1050 \\ 10 & 1300 \\ 11 & 1600 \\ 12 & 2000\end{array}$

All HFJER streams were seeded with a $\mathrm{pH}$ stabilized dispersion of aluminum oxide $(0.4 \mu \mathrm{m}$ particles $)$ in ethanol. The flight stream was seeded with a combination of oil-based foggers. A 'spray-bar' manifold across the opening of the air intake of the flight stream was fed with a pair of foggers, while two foggers positioned in the air inlet house supplemented the high flow conditions. All foggers used oil-based fog fluid and generated 0.5 to $4.5 \mu \mathrm{m}$ particles.

Two-dimensional vector maps from the individual cameras were generated using a multi-pass processing approach. The processing strategy used an initial pass with 64 by 64 pixel subregions on 32 pixel centers followed by 6 passes (using simulated annealing) at 32 by 32 pixel subregions on 16 pixel centers, followed by two final passes using subregion-distortion processing. Symmetric Phase Only Filtering was used to reduce the effect of flare light from the model. All PIV surveys used 400 image pairs per axial station, yielding 400 velocity vector maps at each axial station. The velocity vector maps were then ensemble averaged to compute the first and second order statistics. Hard velocity cutoff limits and Chauvenet's criteria were used to remove outliers before computing statistics. The number of valid measurements was tracked at each velocity point and tallied as a fraction of the 400 total acquisitions made, and the ratio was used to denote the 'quality' of the measurement. Regions where a significant number of bad points were found usually had systematic problems and the data should be ignored. In the plots presented below, data blanking was employed to avoid displaying bad data, or to make the plots easier to visualize. Regions with 'quality' 
metric below 0.8 were blanked. In many plots, particularly of turbulent kinetic energy (TKE), regions where the mean velocity fell below $115 \mathrm{~m} / \mathrm{s}$ were also blanked. This is the velocity of the ambient flow and removing these regions allows better visualization of the more interesting regions of the flow.

\section{Model Hardware}

\section{A. Model hardware configurations}

The installed exhaust concepts evaluated in this test program consisted of nozzles installed above aft decks of the aircraft with variations in an enhanced mixer to shift the noise sources further upstream for increased shielding. In the test, the laser light sheet was directed from below, necessitating that the nozzle and planform be mounted essentially upside down in the facility.

Nozzle: The baseline nozzle had three streams and an external plug. The inner annulus is axisymmetric and thin, carrying approximately half the flow generated by the three-stream engines' tip fan. The second annulus is the primary stream, passing the core and primary fan streams which would be fully mixed upstream in the conceptual engine. It is also axisymmetric. The tertiary nozzle carries the other half of the tip fan flow, and is an annulus that covers roughly half of the circumference of the nozzle. This tertiary stream makes the plume bisymmetric. The total nozzle area was $0.0165 \mathrm{~m}^{2}$, with a primary nozzle diameter of $170 \mathrm{~mm}$.

Chevrons: For the mixing enhancement, the nozzles used chevrons, with varying chevron parameters of location and penetration. Chevrons were applied to a $180^{\circ}$ arc over either side of the primary nozzle. The nomenclature of these locations is given in Figure 4. The two chevron designs had different penetration, but the length and number of chevrons (eight) was the same. The lower-penetration chevrons had an angle $10^{\circ}$ to the centerline, and the higher penetration design had an angle of $16^{\circ}$ to the centerline. Thus, the two chevrons designs could be deployed independently on the two sides of the primary nozzle.

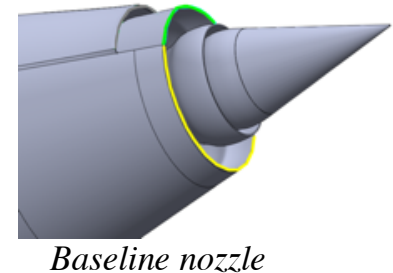

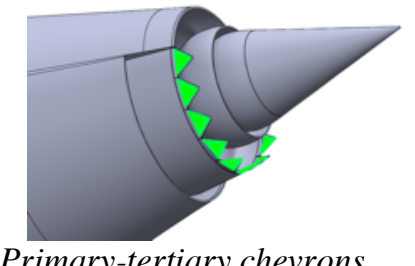

Primary-tertiary chevrons

Figure 4. Nomenclature for locations of chevrons. Note that exhaust system is rotated between views.

Pylons: Two different pylon designs were tested, primarily differing in their standoff and to which nozzle lip they mated. The two different pylon standoffs are shown in Figure 5. The ' $J$ ' planform is the same pylon that was used for the underwing engine installation in an earlier test ${ }^{1}$, but with the tailfin rotated upwards to simulate the top-mounting position. This had a very shallow standoff and only fit on the non-tertiary side of the primary nozzle. More realistically, when the outboard engines are rotated to the topside of the aircraft planform, they must be raised up so that the inlets clear the body of the aircraft. This creates the standoff given by the new planform, designated ' $T$ '. This pylon mates to the tertiary nozzle, as it was expected that having the low-speed tertiary flow on the observer side of the nozzle would produce the most benefit to the observer by lowering the convection speed of turbulence on that side of the jet. 


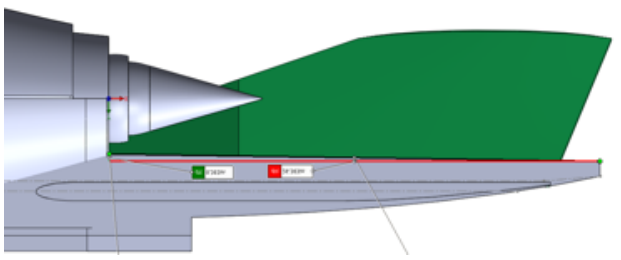

$\begin{array}{cc}\text { Planform } & J \\ \text { Length }[\mathrm{mm}] & 668 \\ \text { Standoff }[\mathrm{mm}] & 10\end{array}$

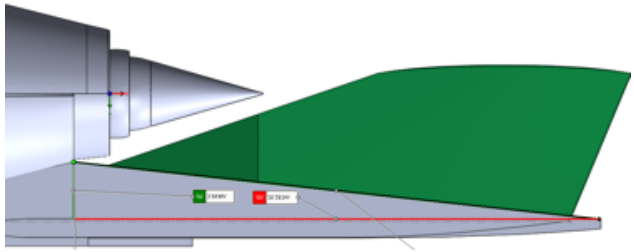

$\begin{array}{cc}\text { Planform } & T \\ \text { Length }[\mathrm{mm}] & 715 \\ \text { Standoff }[\mathrm{mm}] & 78\end{array}$

Figure 5. Planforms and pylons ' $\mathrm{J}$ '( top) and $\mathrm{T}$ ' (bottom).

In summary, the model hardware available for this test consisted of three nearly independent parameters: azimuthal location of chevrons, penetration of those chevrons, and the planform. The matrix of chevron and pylon parameters is given in Table 2. A configuration code was developed to describe configurations: $X Y 0 Z$, where $X, Y, Z$ are numerical values for the chevron designs from Table 2.

Table 2. Hardware components to comprise model configuration

\begin{tabular}{|c|l|}
\hline Component code & Description \\
\hline \multicolumn{2}{|c|}{ Primary-flight lip (X) } \\
\hline 0 & Baseline lip \\
1 & $10^{\circ}$ chevron \\
2 & $16^{\circ}$ chevron \\
\hline \multicolumn{2}{|c|}{ Primary-tertiary lip (Y) } \\
\hline 0 & Baseline lip \\
3 & $10^{\circ}$ chevron \\
4 & $16^{\circ}$ chevron \\
\hline \multicolumn{3}{|c|}{ Planforms (Z) } \\
B & No planform \\
J & Low standoff \\
T & High standoff \\
\hline
\end{tabular}

IV. Flow conditions

The flow conditions were defined from cycles studied under the NASA Low-Noise/Low-Boom Tech Challenge 9 . A three-stream (tip-fan) engine was defined that, when installed on a conceptual supersonic aircraft, met the ICAO Chapter 14 airport noise regulations when programmed lapse rate was implemented. The inverted profile nozzle achieved an acceptable noise level when installed in the two engines-below, one engine-above configuration when the engines were running at a primary nozzle pressure ratio of 1.86. For the PIV portion of this test, the cycle was defined over the pressure ratio range from 1.8 to 2.3 . In the conceptual engine, the primary stream of the nozzle was fed by mixing the core and main fan streams internally, producing a mixed temperature around $560 \mathrm{~K}$ at a pressure ratio $N P R_{p}$ of 2 , and the tertiary fan stream, split between the innermost and tertiary nozzle passages was operating at a pressure ratio $N P R_{f}$ of 1.8 and temperature of $360 \mathrm{~K}$. The flight stream was $M_{\infty}=0.3$ for all test points.

\section{Results}

An extensive set of data were acquired for most configurations of the chevrons and planforms. A subset of the data are covered in the sections below, illustrating the major findings from the full study. For the purposes of understanding jet noise, the most important statistical measures of the flow are mean axial velocity and turbulent kinetic energy, 
which are used in the subsequent plots of the different model configurations. Some definitions are in order before proceeding with the descriptions of results.

The Cartesian coordinates used here are $(x, y, z)$, being the axial, horizontal and vertical directions of the nozzle in flight, with corresponding velocity components $(u, v, w)$. Quantities in angle brackets are averages. Specifically, in PIV acquisition at sample rates well below that of flow timescales, each data point is independent, and the average is a time average if the flow is held steady over the acquisition period. The time average of the velocity $u$ at a point is the mean velocity, $\langle u\rangle$, often shortened to just $U$. Fluctuations of the velocity about the mean is $u^{\prime}=u-\langle u\rangle$ and the variance of the velocity, is $\left\langle u^{\prime} u^{\prime}\right\rangle$. For comparisons with Reynolds-Averaged Navier-Stokes (RANS) computational results, the turbulent kinetic energy is computed from the variances of the velocity components:

$$
T K E=\frac{1}{2}\left(\left\langle u^{\prime} u^{\prime}\right\rangle+\left\langle v^{\prime} v^{\prime}\right\rangle+\left\langle w^{\prime} w^{\prime}\right\rangle\right) .
$$

It is the turbulence that is the feedstock of the acoustic sources. Its distribution is usually correlated with a rough understanding of the distribution of turbulent lengthscales to infer at what frequencies the noise will be generated and how strongly. Gradients of mean axial velocity drive the turbulence and impacts the propagation of the sources. In theoretical developments based on wave packet theory, the mean velocity correlates with the convection velocity and, when coupled with the TKE, indicates the strength of the wave packet sources to the downstream noise. Higher order statistics, such as turbulent lengthscales, require much more data processing and are not presented here.

\section{A. Overall scaling of turbulence levels.}

Part of the analysis is to look at how standard scaling of jet turbulence hold up for more complicated jets, such as the inverted velocity profile plume tested here. Generally, peak TKE is around $2 \%$ of the square of the difference between the jet stream and the ambient stream ${ }^{10}$.

$$
T K E_{\text {peak }} \cong 0.02\left(U_{\text {jet }}-U_{\infty}\right)^{2}
$$

In plumes with coannular streams, there is a choice to make when choosing $U_{\text {jet }}$. In the following discussion we will follow reference [12], choosing $U_{j e t}$ to be $U_{m i x}$, the fully mixed velocity of all the streams, making the comparison more appropriate further downstream. Also, the distributions of turbulent velocity components are such that the variance of axial velocity is roughly half the TKE. That is,

$$
\begin{gathered}
\left\langle u^{\prime} u^{\prime}\right\rangle \cong\left\langle v^{\prime} v^{\prime}\right\rangle+\left\langle w^{\prime} w^{\prime}\right\rangle \\
T K E \cong\left\langle u^{\prime} u^{\prime}\right\rangle
\end{gathered}
$$

These general relationships are taken as hypotheses, and explored by looking at plots of $T K E$ relative to the fully mixed velocity $U_{m i x}$ and of variances relative to TKE.

In Figure 6, turbulent kinetic energy is plotted for the baseline 000B configuration at NPR 1.86, 2.0, and 2.28. The $T K E$ has been normalized by the square of the difference between the fully mixed velocity and the flight stream. The fully mixed velocities for the three flows were 409,432 , and $463 \mathrm{~m} / \mathrm{s}$, respectively. Other values of jet velocity, besides the fully mixed jet velocity, were investigated, such as the velocity of the primary stream, but these did not provide as good of a match between the flow conditions. With this normalization, the TKE is practically identical for all flow conditions, and has a peak value around 0.022 , which is comparable to that found for simple single-stream jets without flight.

Next, the components of the turbulent kinetic energy as a fraction of the TKE are shown. From studies of singlestream jets, the expectation is that the axial component will contribute roughly twice the energy to the TKE as the cross-stream components combined. Or, equivalently, the variance of the axial velocity will have a value equal to the $T K E$. As seen in Figure 7, this hypothesis is borne out by the data for the plume of the inverted velocity profile nozzle as well. Near the nozzle, the axial component is measured to be nearly $20 \%$ greater than downstream, but downstream of $350 \mathrm{~mm}$, well before the end of the potential core, the contour plots show the ratio of axial variance and $T K E$ to be close to 1 . 
(a)
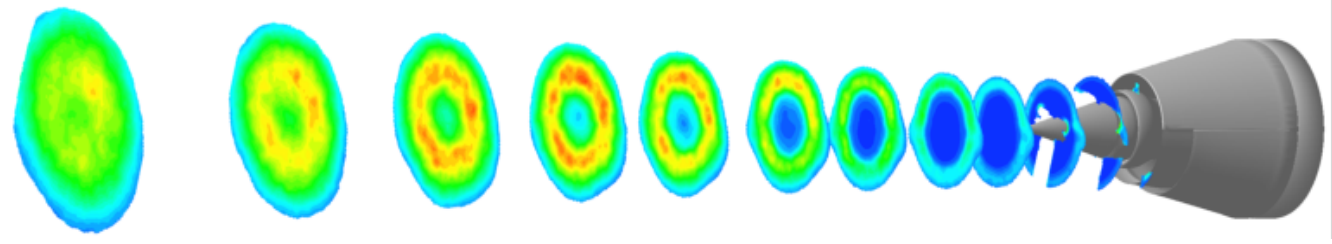

(b)
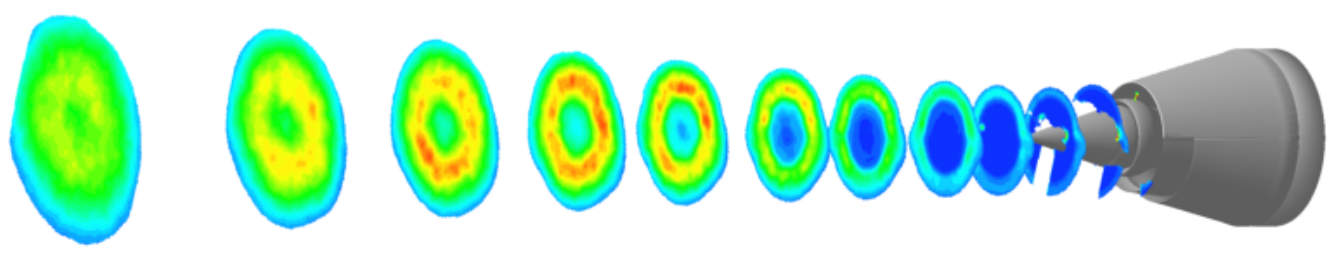

(c)
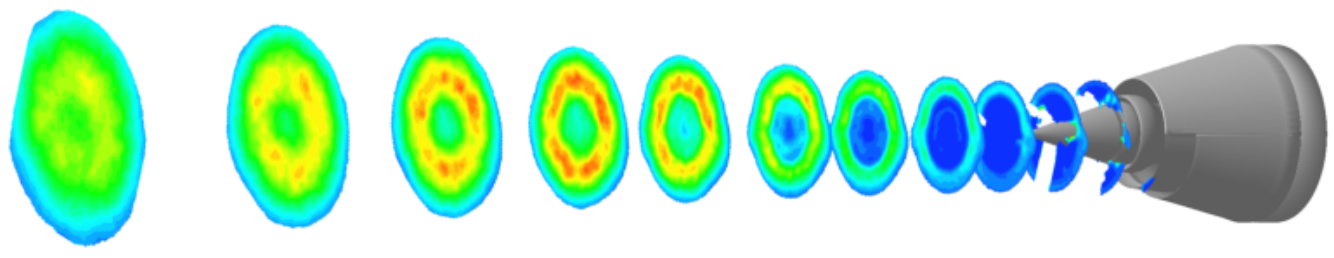

Figure 6. Turbulent kinetic energy normalized by velocity difference between fully mixed jet and ambient. Configuration 000B at primary $\mathrm{NPR}_{\mathrm{p}}=($ a) 1.8 , (b) 2.0, (c) 2.3. Data is blanked for velocities below $115 \mathrm{~m} / \mathrm{s}$. Axial locations given in Table 1.

$U[\mathrm{~m} / \mathrm{s}]>115$
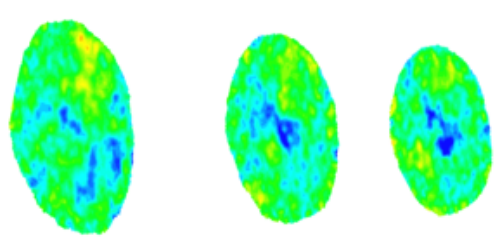
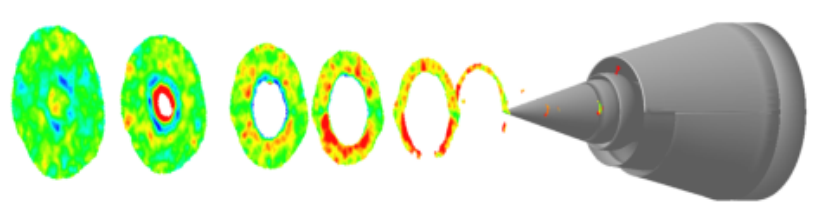

Figure 7. Axial component of turbulent kinetic energy (variance of axial velocity) as a fraction of TKE for configuration 000B at $\mathrm{NPR}_{\mathrm{p}}=2.0$. Data is blanked for $\mathrm{TKE} /\left(\mathrm{U}_{\mathrm{mix}}-\mathrm{U}_{\infty}\right)^{2}<0.005$. Axial locations given in Table 1 .

\section{B. Impact of chevron penetration and location for the uninstalled nozzle.}

A major objective of the test was to determine the impact of the chevrons on the flow and noise. In the following, the flow from different chevron penetrations and locations are shown for the uninstalled nozzle. Overview plots of the mean axial velocity and TKE are shown first, followed by detailed cross-sections near the nozzle.

First, consider the impact of chevron penetration for chevrons mounted on the primary nozzle between the primary and flight streams. Figure 8 shows the mean axial velocity for the baseline (no chevrons) nozzle and nozzles with two different penetrations. The chevrons on the top half of the nozzle mix out the high speed annulus on that side rather quickly (quicker with more penetration), but interestingly, the 'potential core' of primary flow persists further downstream for the chevron nozzles.

The chevrons have a significant impact on the TKE, as expected. Compared with the baseline (no chevron) nozzle on the top plot of Figure 9, the TKE is significantly reduced on the side of the nozzle with the chevrons. The 100B nozzle, while greatly reducing the peak $T K E$ on the chevron side of the plume, had a slightly more energetic $T K E$ on the non-chevron side than the baseline nozzle. The 200B nozzle, with greater penetration, showed reductions on all sides of the plume. The increase in TKE near the nozzle, seen in the 'fingers' of TKE from the chevrons, may be underrepresented due to the thin shear layer being under-resolved by the PIV at those stations. The most noticeable difference between the two chevrons designs was the lower peak TKE for the 200B nozzle. The 200B had $25 \%$ lower $T K E$ on the non-chevron side where the peak TKE occurs. 
(a)
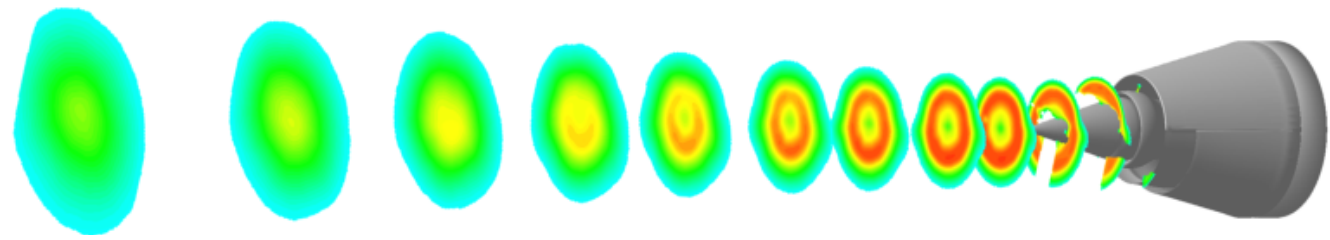

(b)
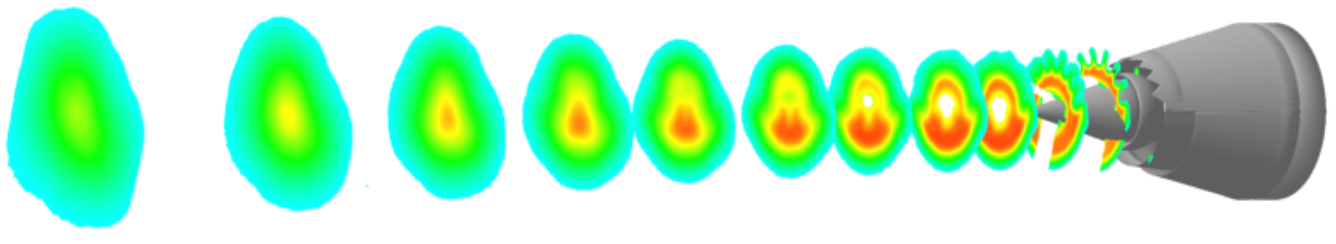

(c)
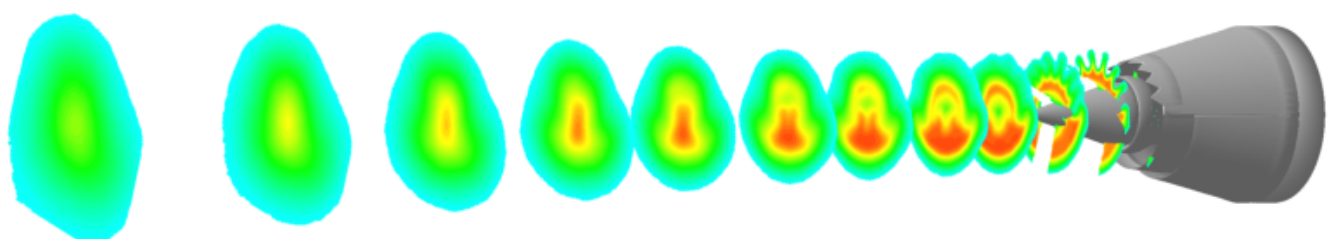

Figure 8. Mean axial velocity for (a) 000B, (b) 100B, (c) 200B nozzles at NPRp=2.0. Data is blank for $\mathrm{U}<$ $115 \mathrm{~m} / \mathrm{s}$. Axial locations given in Table 1.

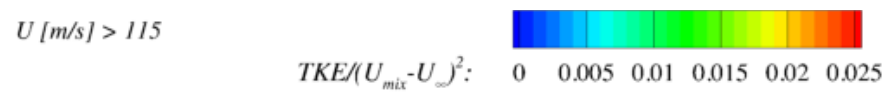

(a)
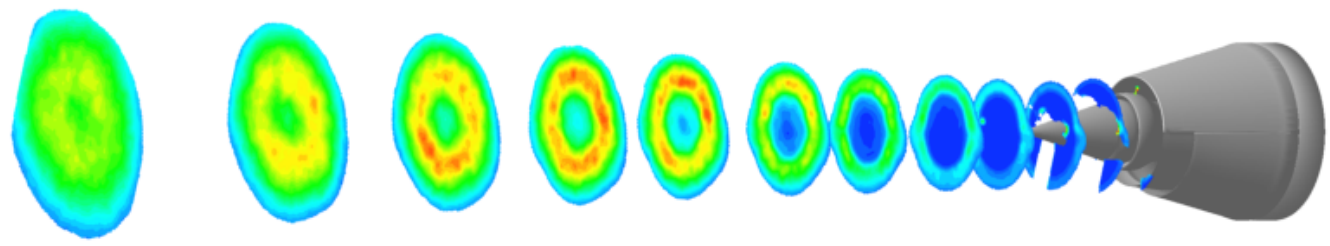

(b)
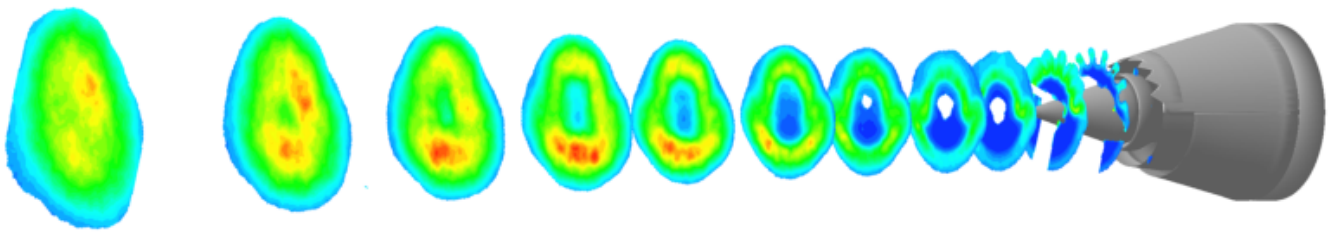

(c)
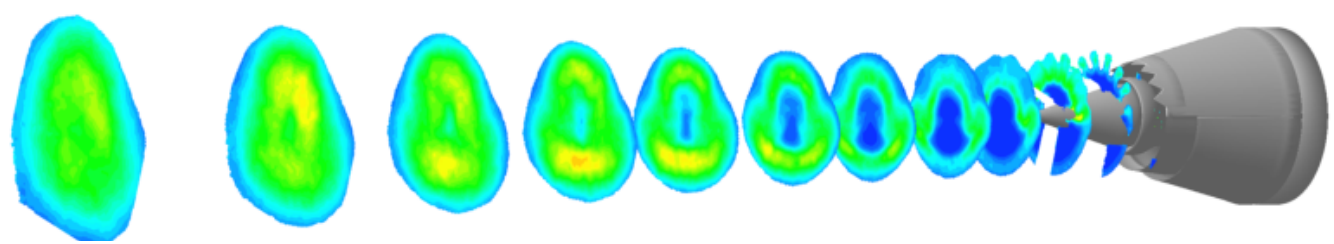

Figure 9. Normalized turbulent kinetic energy for (a) 000B, (b) 100B, (c) 200B nozzles at NPRp=2.0. Data is blank for $\mathrm{U}<115 \mathrm{~m} / \mathrm{s}$. Axial locations given in Table 1.

Looking more closely at the first few axial planes (Figure 10), the chevrons create an immediate convolution of the shear layer with a doubling of the recorded TKE over the baseline nozzle at the first plane. The peak TKE of 200B is almost double that of 100B by the increased penetration design. There was little difference in the structure of the lobed shear layer between the two chevron designs. At $150 \mathrm{~mm}$ there is a dramatic difference in the TKE between the baseline and chevron nozzles, with the 200B again having significantly higher levels, but similar spatial structure. By $250 \mathrm{~mm}$ downstream the bulk of the shear layer downstream of the chevrons has relaxed back to a smooth arc with only a slightly larger TKE level than the baseline. There are a pair of high-TKE regions at the ends of the arc of 
chevrons that persist downstream, the ones in the 200B configuration being slightly more energetic than that of the 100B. At all locations, the shear layer on the side of the flow opposite the chevrons was the same as the baseline.

(a)

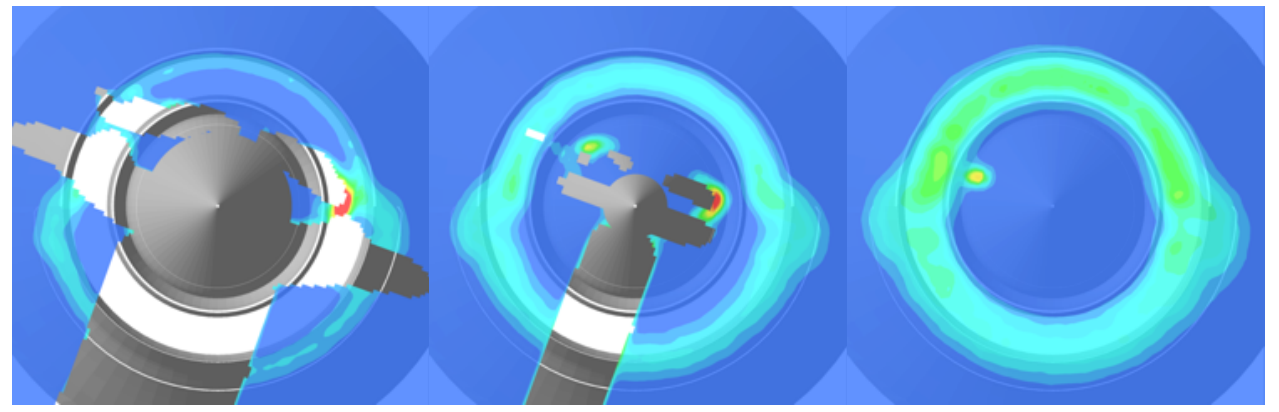

(b)

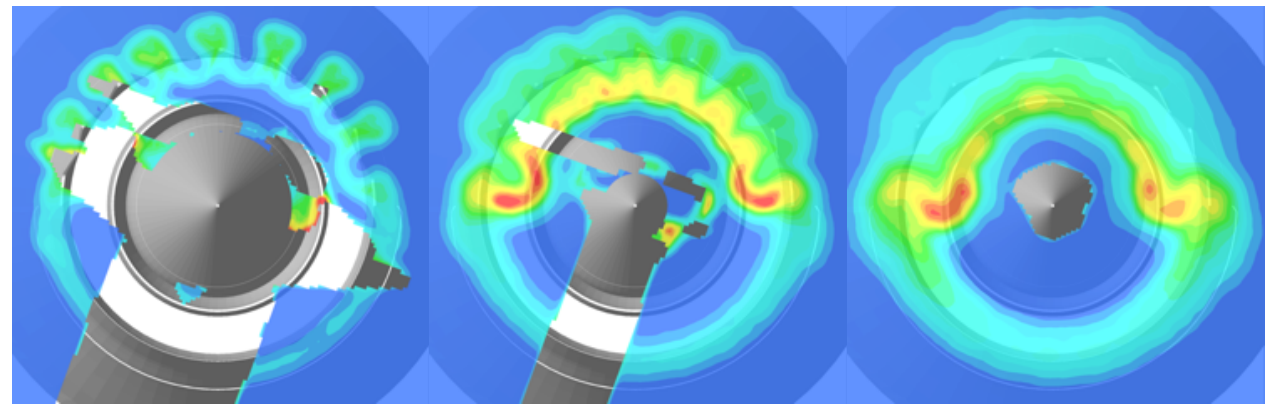

(c)

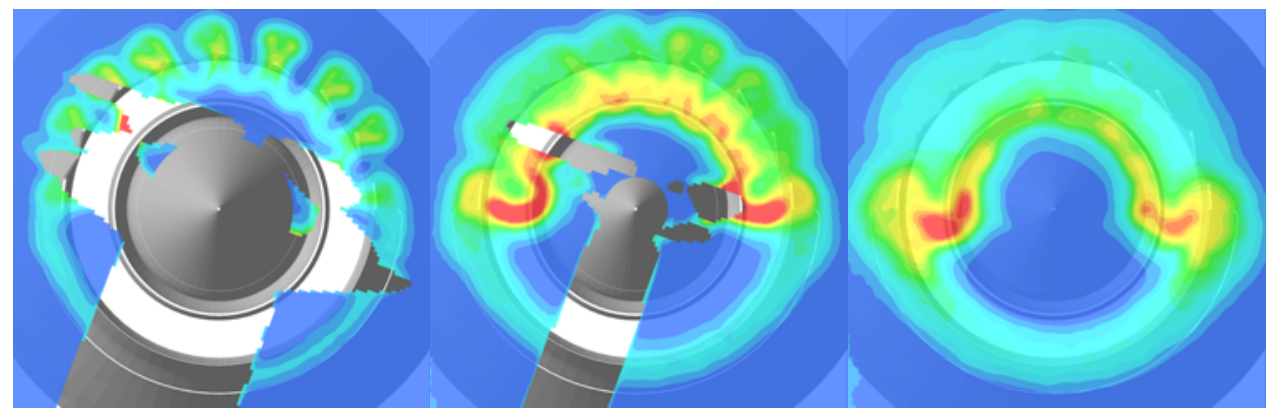

$70 \mathrm{~mm}$

$150 \mathrm{~mm}$

$250 \mathrm{~mm}$

Figure 10. Turbulent kinetic energy at $x=70,150,250 \mathrm{~mm}$ for the (a) $000 \mathrm{~B}$, (b) 100B, and (c) 200B configurations at $\mathrm{NPRp}=\mathbf{2 . 0}$.

Next, consider the impact of chevron placement, comparing chevrons mounted on different sides of the primary nozzle. The nozzle just considered, 200B, had the chevrons between the primary and flight streams. This nozzle is compared with nozzle 040B with the chevrons on the primary nozzle lip between the primary and tertiary streams. The chevron penetrations of the 200B and 040B nozzles were roughly equivalent, simply placed on opposite sides of the primary nozzle. Configuration 240B combined both of these sets of chevrons, and had chevrons all around the primary nozzle lip.

The difference in chevron location is very apparent in Figure 11. The primary flow on the side of the nozzle with chevrons mixes out much faster than the side without chevrons, and so at first glance the 200B and 040B flows appear to be vertical mirror opposites. Some small details are visible in the mean velocity profiles that show there is a difference when the chevrons have the flight stream $(U=102 \mathrm{~m} / \mathrm{s})$ or the tertiary stream $(U=330 \mathrm{~m} / \mathrm{s})$ on the low-speed side. The mixing is not quite as quick in the latter case $(040 \mathrm{~B})$ by $x=500 \mathrm{~mm}$. However, the apparent end of the potential core, where the peak velocity falls below the initial primary stream is around $1300 \mathrm{~mm}$ for both nozzles. When the chevrons are applied to both sides, the upper side, with the 200B chevrons, does mix faster than the side with the 040B chevrons. With chevrons on both sides, the cumulative mixing is faster than with chevrons on only one side, and the end of the potential core is closer to $1000 \mathrm{~mm}$. 
The biggest difference in the chevron placement is in the TKE. In Figure 12, the peak TKE occurs on the side without chevrons, but the peak of the 200B flow is around $T K E /\left(\mathrm{U}_{\text {mix }}-\mathrm{U}_{\infty}\right)^{2}=0.02$ at $\mathrm{x}=1030 \mathrm{~mm}$. The peak of the $040 \mathrm{~B}$ flow is much higher, peaking at the same axial distance but at a value of 0.025 . This is apparently a consequence of the higher shear between the primary and flight on the non-chevron side of the 040B nozzle, compared with the primary to tertiary stream on the non-chevron side of the 200B nozzle. The 200B chevrons were in a velocity gradient of $\left(U_{\mathrm{p}}-U_{\mathrm{t}}\right) /\left(U_{\mathrm{p}}+U_{\mathrm{t}}\right)=0.17$, while the 040B chevrons were in a velocity gradient of $\left(U_{\mathrm{p}}-U_{\infty}\right) /\left(U_{\mathrm{p}}+U_{\infty}\right)=0.61$. With chevrons on both sides, the 240B nozzle had relatively low TKE levels throughout the plume, peaking at 0.017 .

$U[\mathrm{~m} / \mathrm{s}]>115$

$$
U[\mathrm{~m} / \mathrm{s}]: \quad 0 \quad 100200300400
$$

(a)
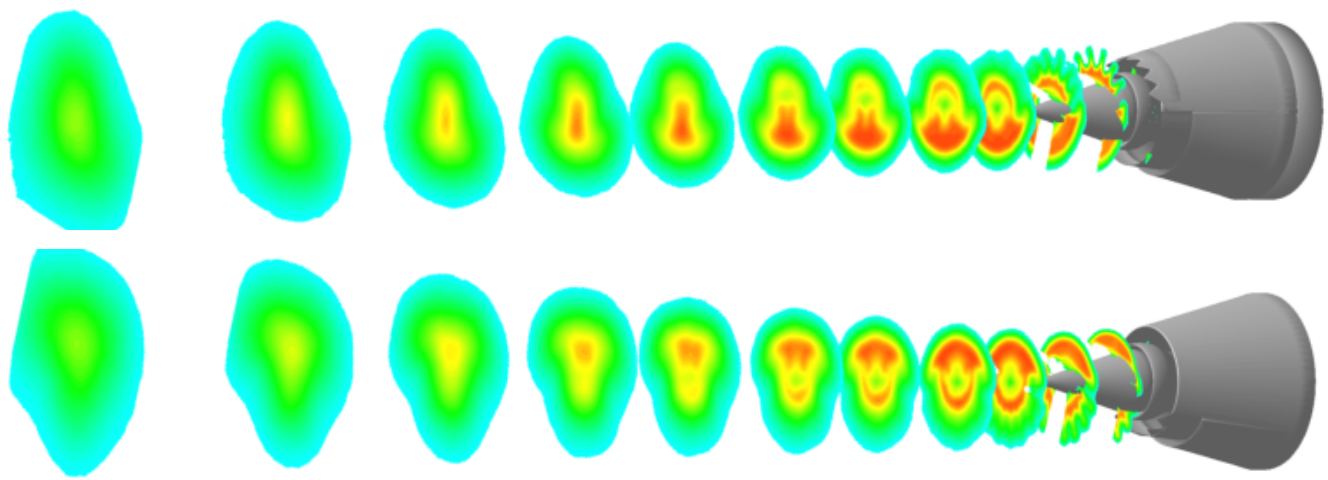

(b)
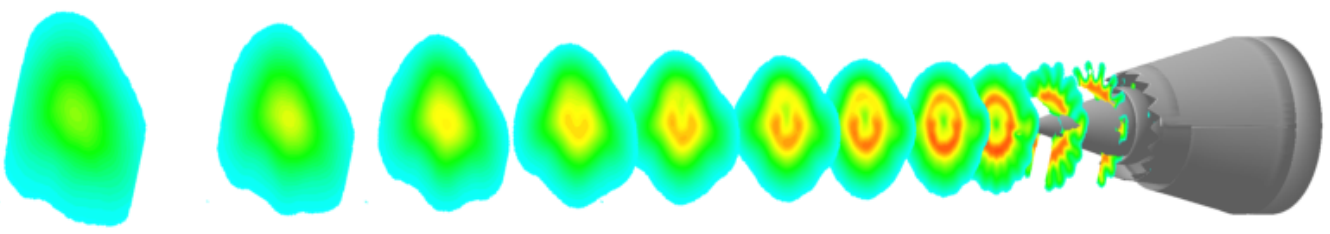

(c)

Figure 11. Mean axial velocity for (a) 200B, (b) 040B, (c) 240B nozzles at NPRp=2.0. Data is blank for $U<$ $115 \mathrm{~m} / \mathrm{s}$. Axial locations given in Table 1.

(a)
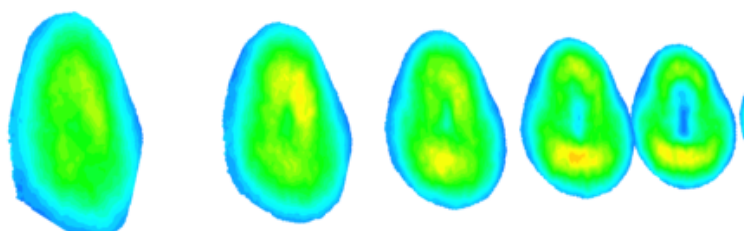

$T K E /\left(U_{\operatorname{mix}}-U_{\infty}\right)^{2}:$
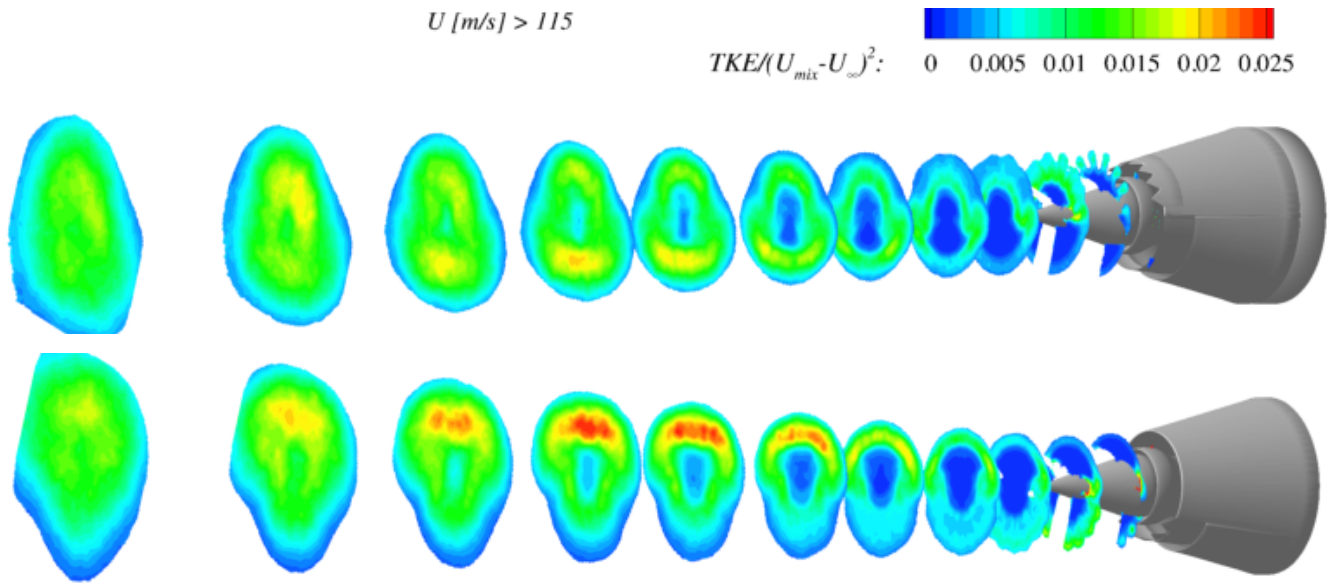

(b)
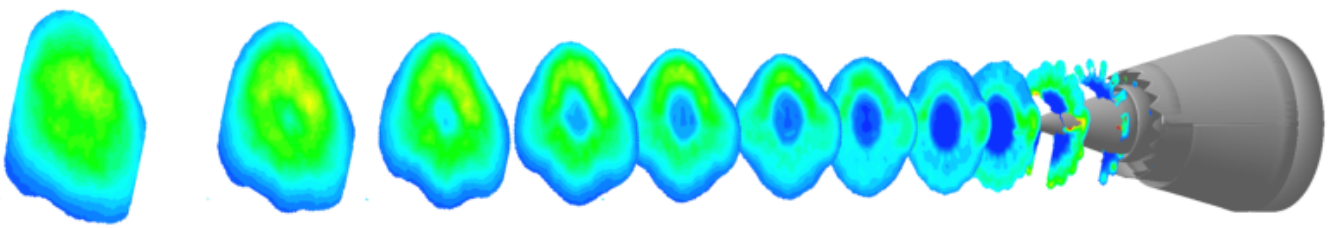

(c)

Figure 12. Normalized turbulent kinetic energy for (a) 200B, (b) 040B, (c) 240B nozzles at NPRp=2.0. Data is blank for $U<115 \mathrm{~m} / \mathrm{s}$. Axial locations given in Table 1 . 
Figure 13 looks more closely at the first few planes, where the effects of the chevrons are most apparent. The most striking difference in the TKE between the $200 \mathrm{~B}$ and 040B nozzles is at $\mathrm{x}=150 \mathrm{~mm}$ where the $200 \mathrm{~B}$ chevrons have peak $T K E$ on the innermost lobes of the shear layer, while the 040B has peak TKE on the outermost lobes of the shear layer. At $70 \mathrm{~mm}$, the TKE of the 040B flow is less than that of the 200B flow, presumably because of the reduced shear between the primary and tertiary streams. However, at $150 \mathrm{~mm}$, the peak levels are similar, albeit at different parts of the lobed shear layer. The end vortices at $x=250 \mathrm{~mm}$ are stronger in the $200 \mathrm{~B}$ flow.

The early flow field of the combo nozzle, 240B, is virtually a superposition of the 200B and 040B nozzle flows. The two chevron systems only interact by the third plane, $x=250 \mathrm{~mm}$, where the end vortices are strengthened significantly above that of either the 200B or 040B flows. It is surmised that the vortices from the last of the two chevron sets must strengthen each other.

(a)

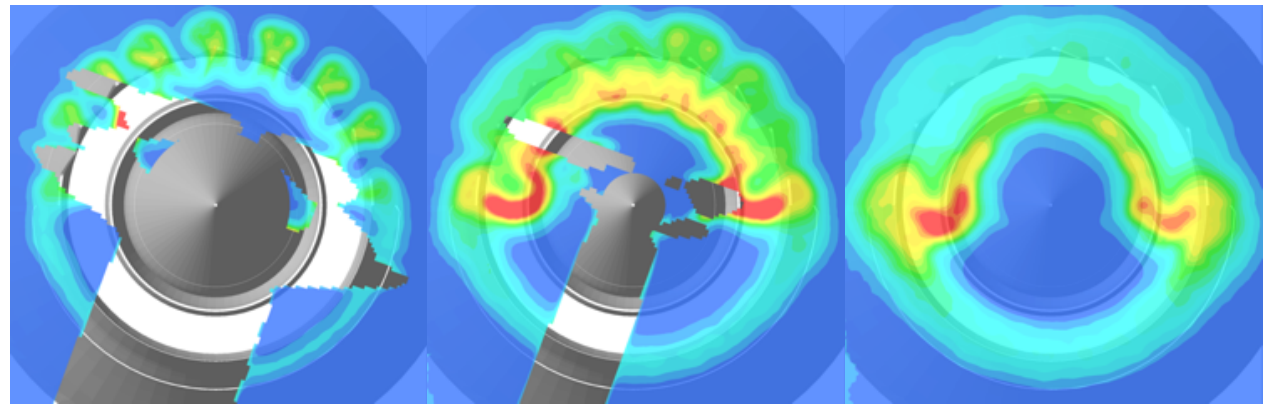

(b)

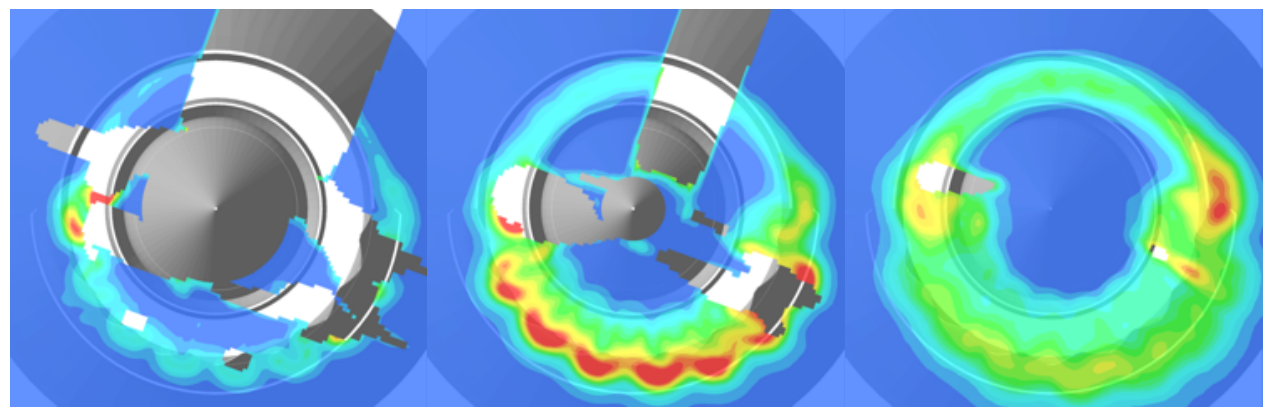

(c)

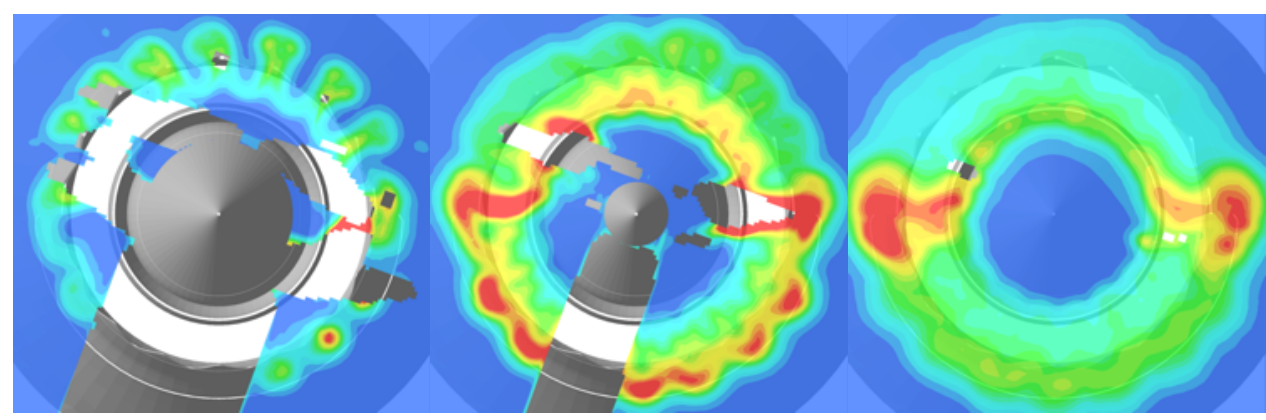

$70 \mathrm{~mm}$

$150 \mathrm{~mm}$

$250 \mathrm{~mm}$

Figure 13. Turbulent kinetic energy at $x=70,150,250 \mathrm{~mm}$ for the (a) 200B, (b) 040B, and (c) 240B configurations at $\mathbf{N P R p}=2.0$.

\section{Impact of installation and planform standoff for the baseline nozzle.}

Having looked at the flow fields of the uninstalled baseline IVP nozzle, with various chevrons applied, the next step is to see how these flow fields are modified by the presence of the aft deck of an aircraft. In the simplest case, the flow fields would remain unchanged and the planform would only serve as an acoustic shield of the propagating noise. Work with single-stream jets near flat plates have shown that as the surface gets near the jet plume, however, the jet plume is strongly distorted, and a secondary shear layer can form off the trailing edge of the planform, resulting in a new source of noise. 
The first investigation, therefore, is to examine the flow of the baseline nozzle with the installation of two planforms with similar axial coverage but different standoffs. As shown Figure 5, the comparison is not just in amount of standoff but also in location relative to the tertiary stream. The 'J' planform with smaller standoff has a pylon that emerges from the primary lip on the flight stream side and has very little drop away from the nozzle to the trailing edge. The ' $T$ ' planform with larger standoff has a pylon that emerges from the primary lip on the tertiary annulus side and has significant drop away to the trailing edge. The difference in standoff is almost half a jet diameter. Making things even more complicated, the actual planform trailing edge is some $25 \mathrm{~mm}$ above the trailing edge of the pylon in the ' $\mathrm{J}$ ' planform, but the two are roughly flush in the ' $\mathrm{T}$ ' planform. Finally, the tertiary stream is between the pylon and the primary stream ' $\mathrm{T}$ ' configuration, but not in the ' $\mathrm{J}$ ' configuration.

With these differences in geometry noted, the flows are shown as before, first as comparisons of mean axial velocity in Figure 14. The uninstalled nozzle flow is included to aid in comparisons. In general, the impact on the mean velocity is minimal, the decay of the primary stream taking roughly the same axial extent with or without the planform installed. The main difference is in the distortion of lower velocity plume contours on the side facing the pylon. The jet flow tries to stay attached to the pylon, causing a low-speed finger to be extracted from the jet.

Even the TKE shows minimal distortion due to the installation, as shown in Figure 15. The TKE levels seem to be slightly lower in the shear layer of the 000J configuration upstream of the planform trailing edge, but these differences are only barely outside expected experimental error. The TKE just aft of the $000 \mathrm{~J}$ planform shows that the shear layer is pulled down over a small section near the pylon, but this has no significant effect on the TKE levels here or downstream.

(a)
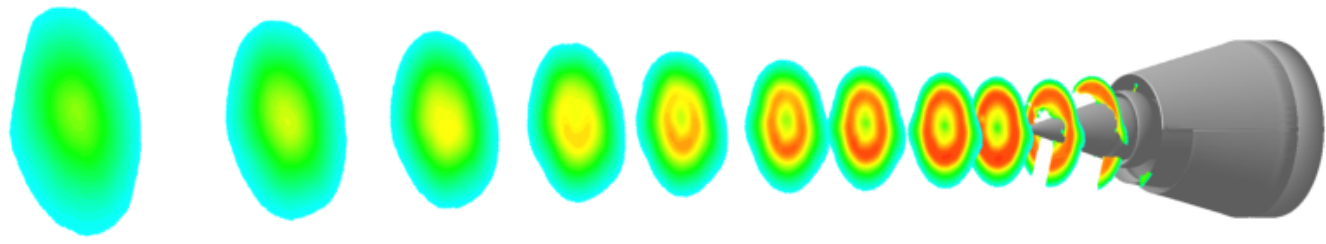

(b)
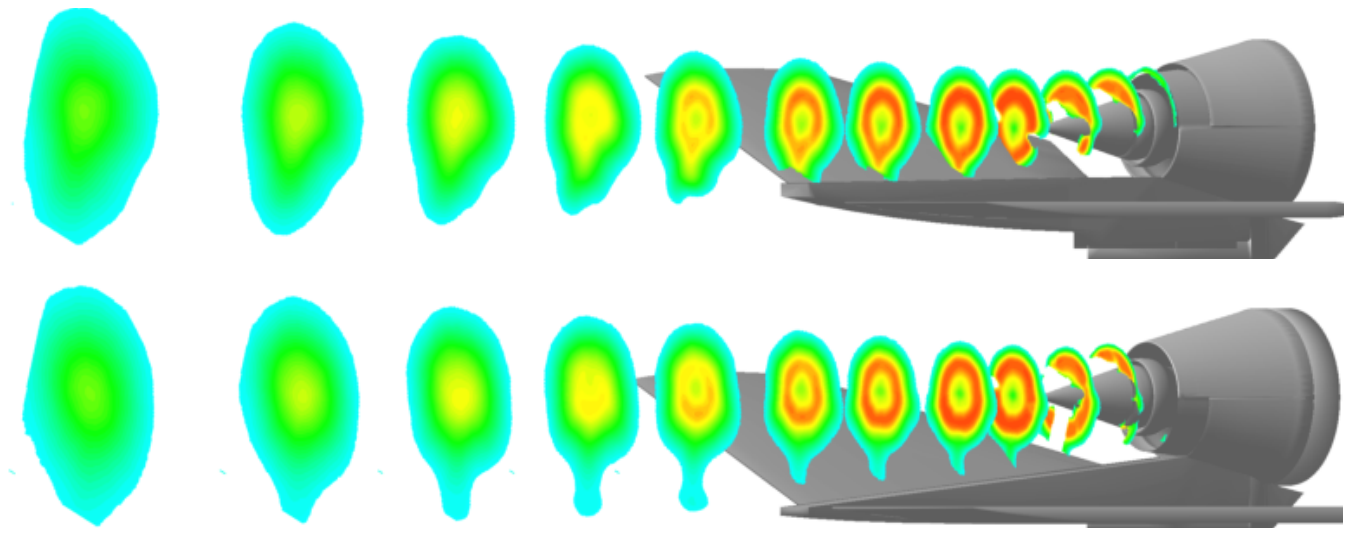

Figure 14. Mean axial velocity for (a) 000B, (b) 000J, (c) 000T configurations at NPRp=2.0. Data is blank for $\mathrm{U}<115 \mathrm{~m} / \mathrm{s}$. Axial locations given in Table 1 . 
(a)
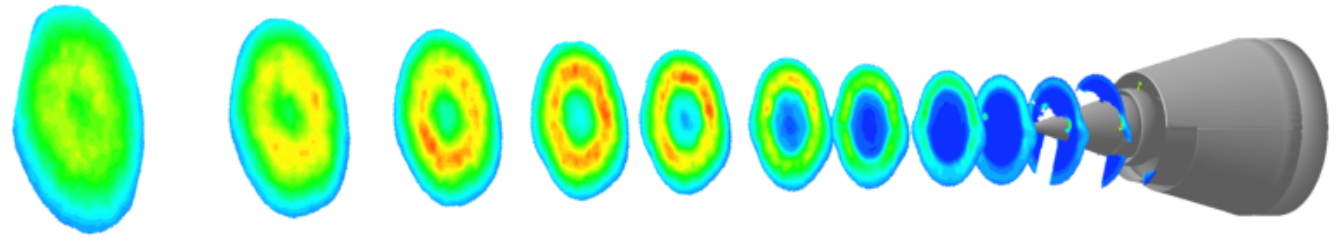

(b)
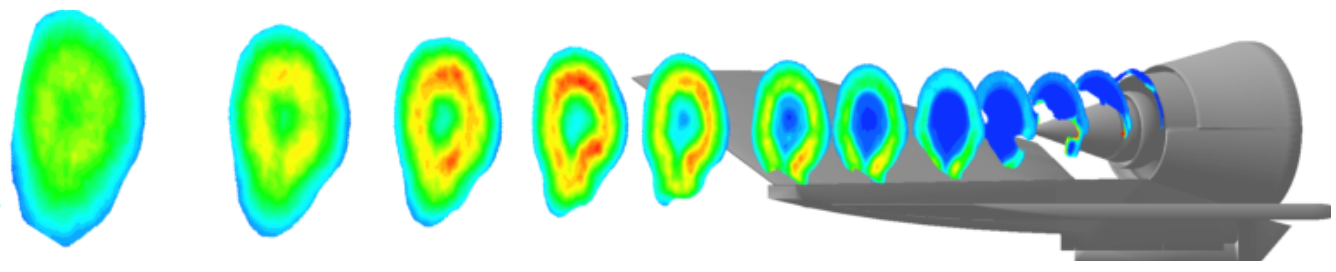

(c)
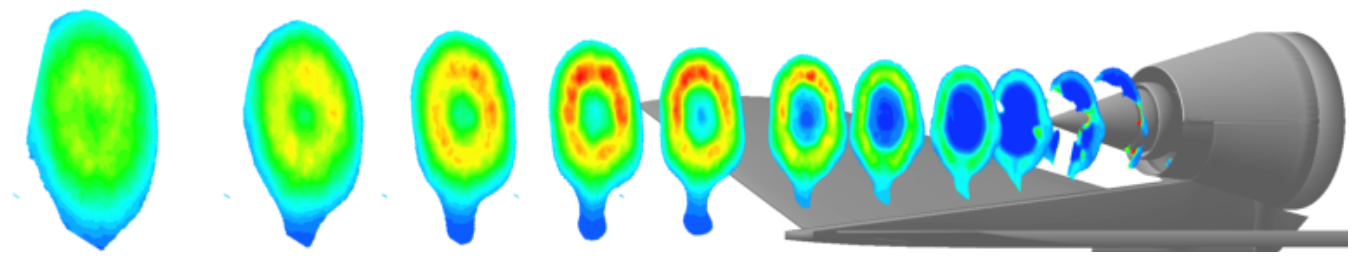

Figure 15. Normalized turbulent kinetic energy for (a) 000B, (b) 000J, (c) 000T configurations at NPRp=2.0. Data is blank for $U<115 \mathrm{~m} / \mathrm{s}$. Axial locations given in Table 1.

Just how the difference in pylon standoff affects the shear layer is more clear when looking at TKE at the planes just upstream and downstream of the trailing edge. In Figure 16, the high speed primary flow of the 000J configuration stays attached to the pylon for a significant distance downstream of the nozzle, generating a shear layer strongly bent toward the pylon near the trailing edge. The dominant shear layer between primary and tertiary streams near the pylon of the 000T configuration stays unattached even as a part of the tertiary flow is pulled down to the pylon surface. This keeps the dominant shear layer, and its $T K E$, far enough off the plate that it is not distorted. There is a slight reduction of $T K E$ on the pylon side, presumably because the tertiary flow is not in contact with the lower speed flight stream above the pylon, maintaining its original shear with the primary instead of increasing it with a lowered velocity.

Overall, the impact of the installation on the baseline IVP nozzle is very minimal. 
(a)

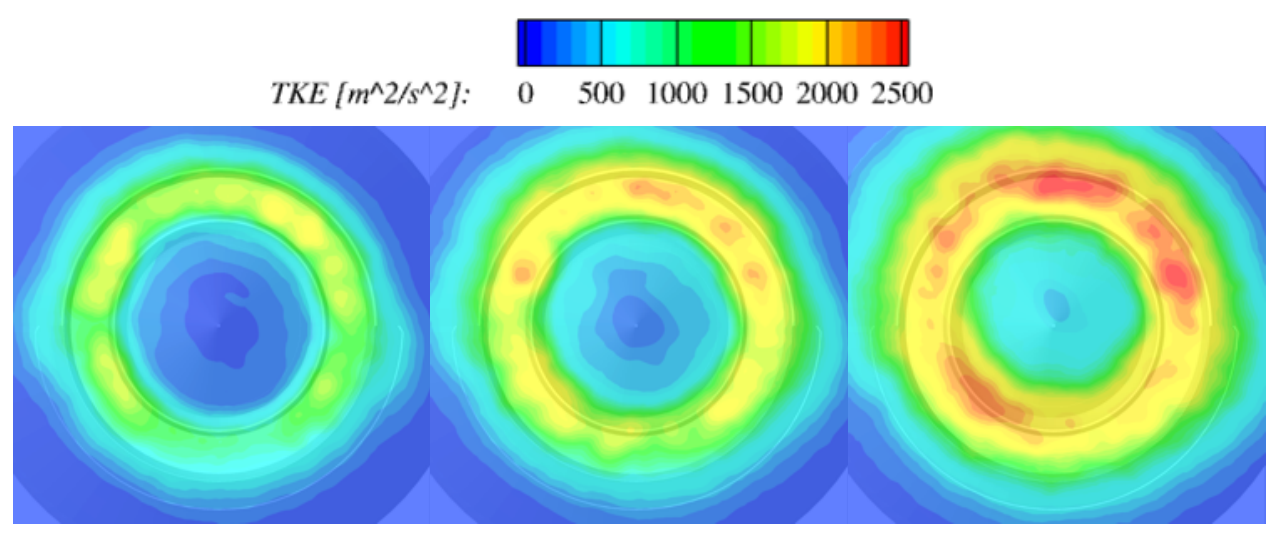

(b)

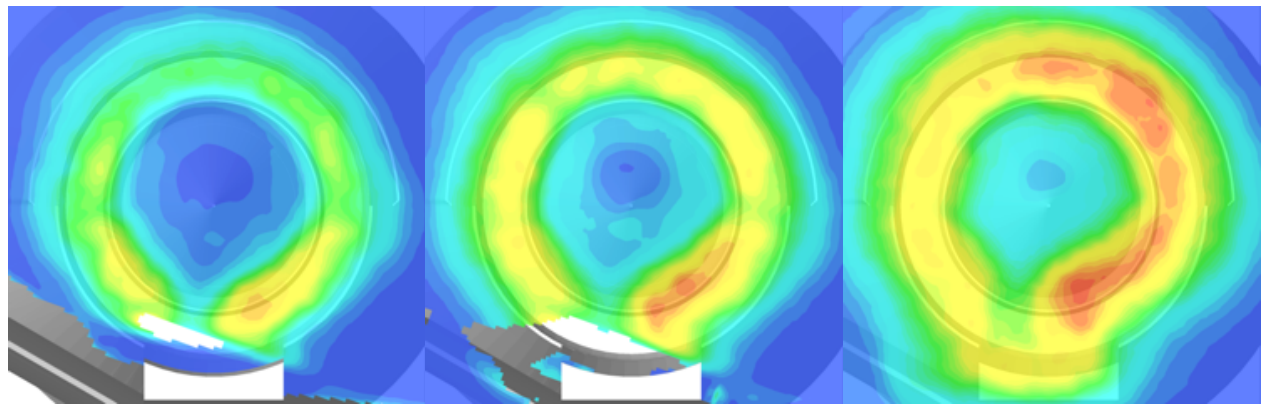

(c)

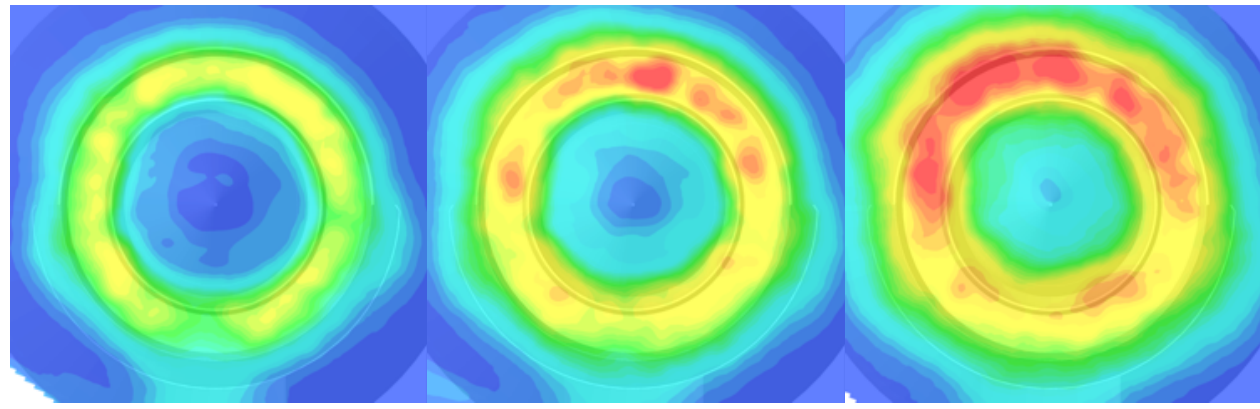

$500 \mathrm{~mm}$

$650 \mathrm{~mm}$

$850 \mathrm{~mm}$

Figure 16. Turbulent kinetic energy at $x=500,650,850 \mathrm{~mm}$ for the (a) 000B, (b) 000J, and (c) 000T configurations at $\mathrm{NPR} \mathbf{p}=\mathbf{2 . 0}$.

\section{Impact of the chevron penetration and location for installed nozzle}

Finally, the impact of installation on the nozzles with chevrons is explored. For these, only the ' $\mathrm{T}$ ' planform, with the high standoff, was acquired. To directly answer what the effect of installation is on the jet plumes for these chevron nozzles, the uninstalled and installed $T K E$ plots are presented juxtaposed.

The 200B/200T configurations at $N P R p=2.0$ are shown in Figure 17. Since the chevrons on the top of the nozzle had little impact on the lower shear layer when it was uninstalled, it is not surprising that the impact of installation is very small. As happened when the baseline nozzle was installed on the planform there was a slight finger of flow extended down from the cross-sections as the flow attempted to attach to the pylon. This is mostly observed in the contour level of $\mathrm{U}=115 \mathrm{~m} / \mathrm{s}$ that was used in blanking the $T K E$ data; The $T K E$ itself is minimal in this finger of flow.

When the chevrons were installed on the bottom of the nozzle primary lip (configurations 040B/040T, Figure 18) there was still very little difference in the TKE contours when the planform was installed. Perhaps this is because the shear layer modified by the chevrons was buffered by the tertiary stream between primary stream and the pylon. If anything, the upper shear layer was slightly changed by installation of the planform, being stronger with the planform in place.

Given how little impact the planform had on the 200 and 040 chevrons separately, it is not surprising that it also had little impact on the 240 nozzle with both chevron systems (Figure 19). 
(a)
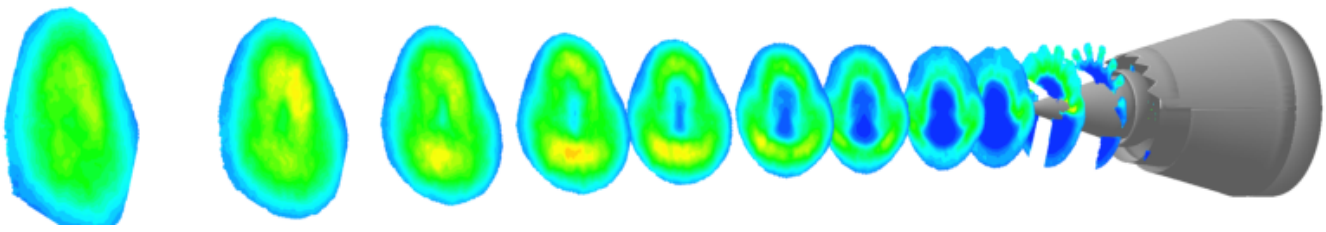

(b)
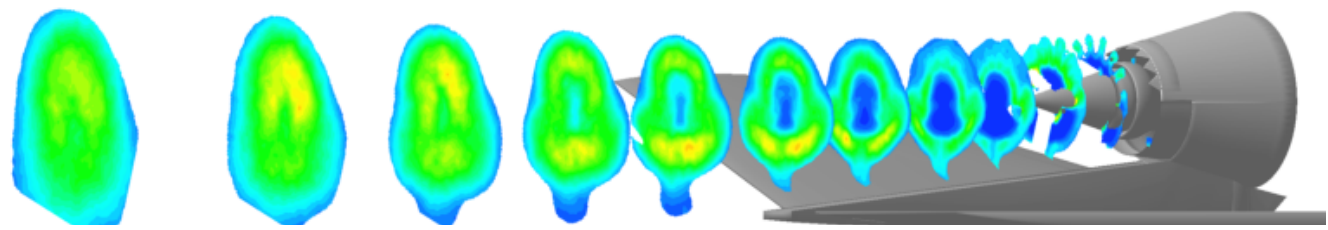

Figure 17. Normalized turbulent kinetic energy for (a) 200B, (b) 200T configurations at NPRp=2.0. Data is blank for $\mathrm{U}<115 \mathrm{~m} / \mathrm{s}$. Axial locations given in Table 1.

(a)
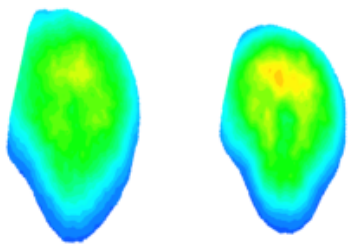

$U[\mathrm{~m} / \mathrm{s}]>115$

TKE/(U $\left.U_{\text {mix }}-U_{\alpha^{\prime}}\right)^{2}: \quad \begin{array}{lllllll}0 & 0.005 & 0.01 & 0.015 & 0.02 & 0.025\end{array}$

(b)
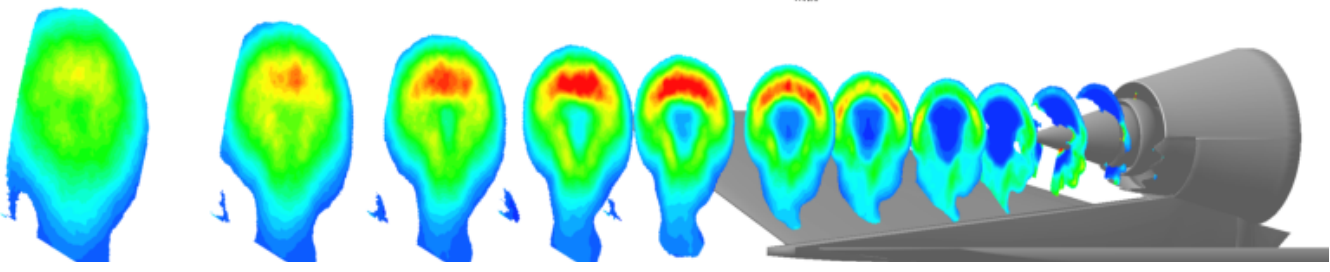

Figure 18. Normalized turbulent kinetic energy for (a) 040B, (b) 040T configurations at NPRp=2.0. Data is blank for $\mathrm{U}<115 \mathrm{~m} / \mathrm{s}$. Axial locations given in Table 1.

$U[\mathrm{~m} / \mathrm{s}]>115$

$\begin{array}{lllllll}T K E /\left(U_{\operatorname{mix}}-U_{\infty}\right)^{2}: & 0 & 0.005 & 0.01 & 0.015 & 0.02 & 0.025\end{array}$

(a)
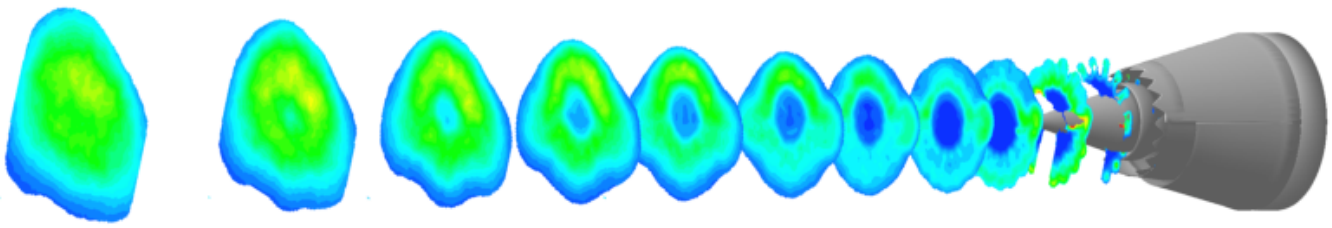

(b)
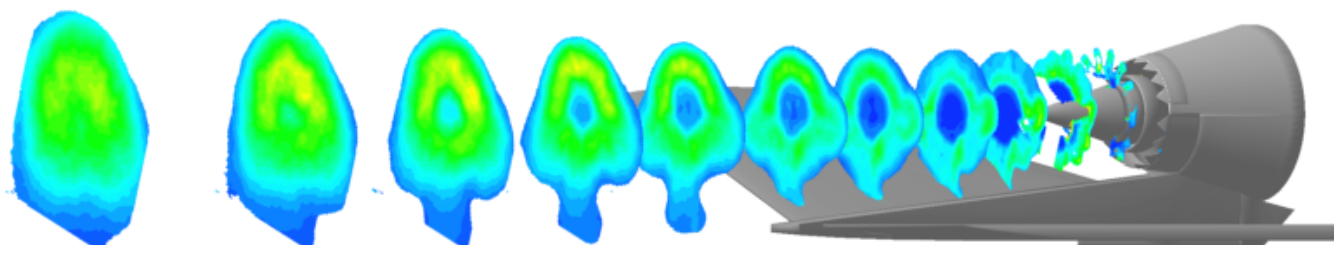

Figure 19. Normalized turbulent kinetic energy for (a) $240 \mathrm{~B}$, (b) $240 \mathrm{~T}$ configurations at $\mathrm{NPRp}=2.0$. Data is blank for $U<115 \mathrm{~m} / \mathrm{s}$. Axial locations given in Table 1 .

For completeness, details of the cross-sections of TKE at stations upstream and downstream of the planform trailing edge are given for the nozzles with high penetration chevron, with and without the planform in place. Looking at the 
pairs of cross-sections for the 200B nozzle (Figure 20), there is evidence that the planform slightly augmented the TKE on the lower half of the shear layer, perhaps because it lowered the flight speed on the side of the planform. Similarly, the presence of the planform increased the TKE on the side opposite the chevrons for the 040 nozzle as well (Figure 21).

For the 240 nozzle, with chevrons all around the primary lip, the planform had the effect of increasing the TKE everywhere, but only by less than $5 \%$, an increase that is very much smaller than the changes coming from variations in chevron design and location. Again, the impact of installation was very small.

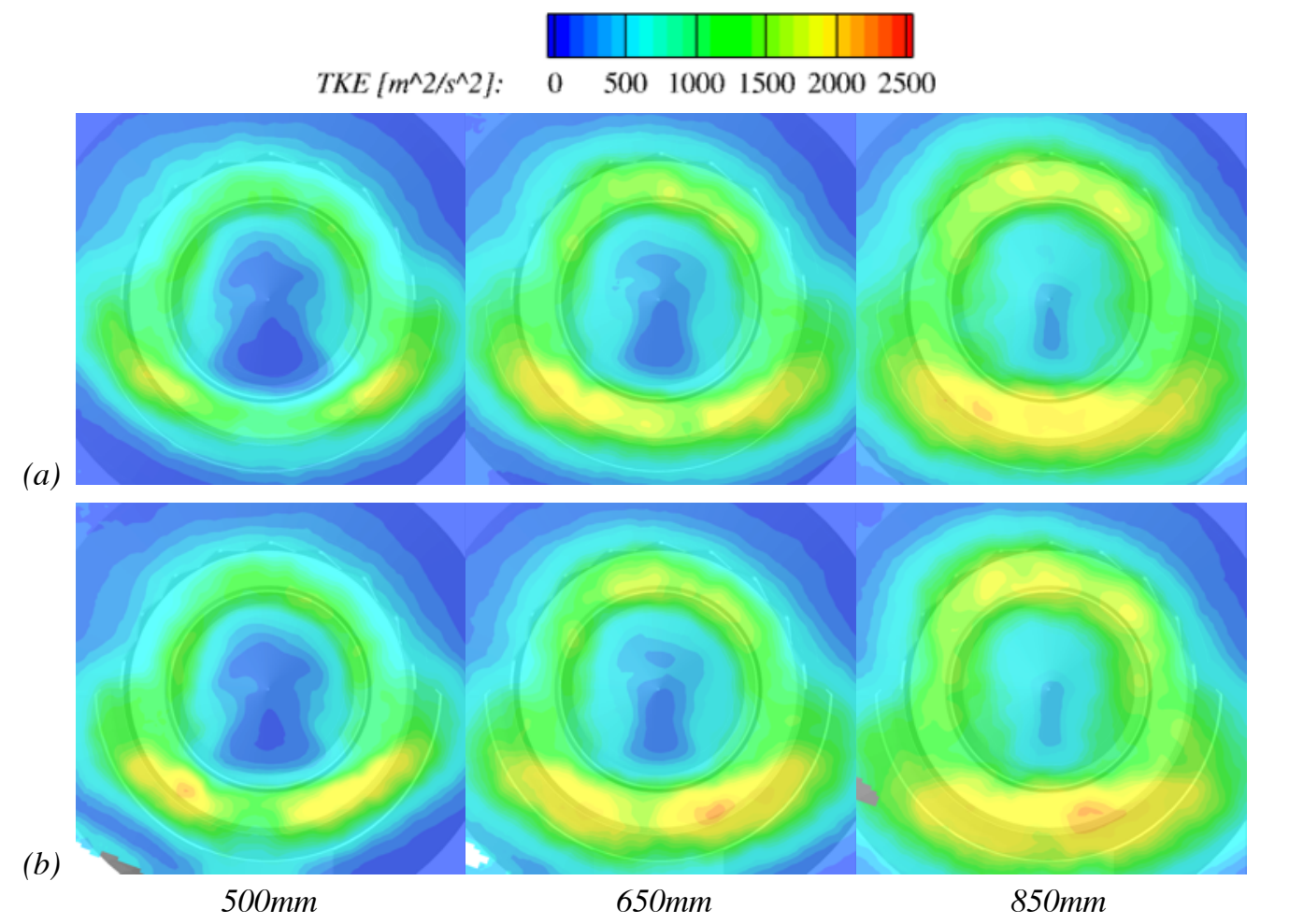

Figure 20. Turbulent kinetic energy at $x=500,650,850 \mathrm{~mm}$ for the (a) 200B, (b) 200T configurations at NPRp $=2.0$. 


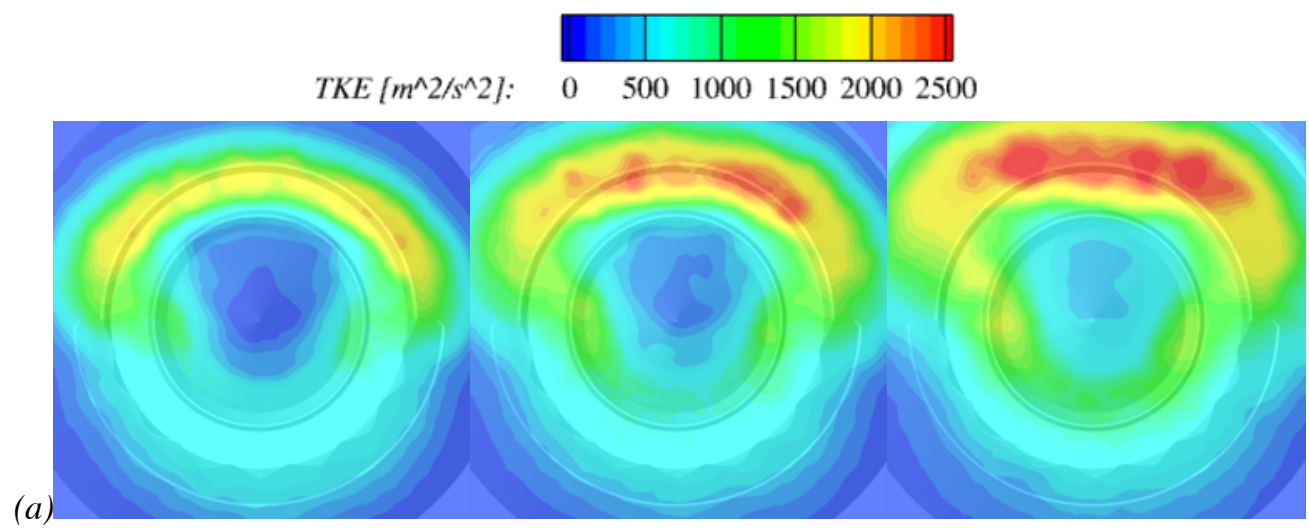

(b)

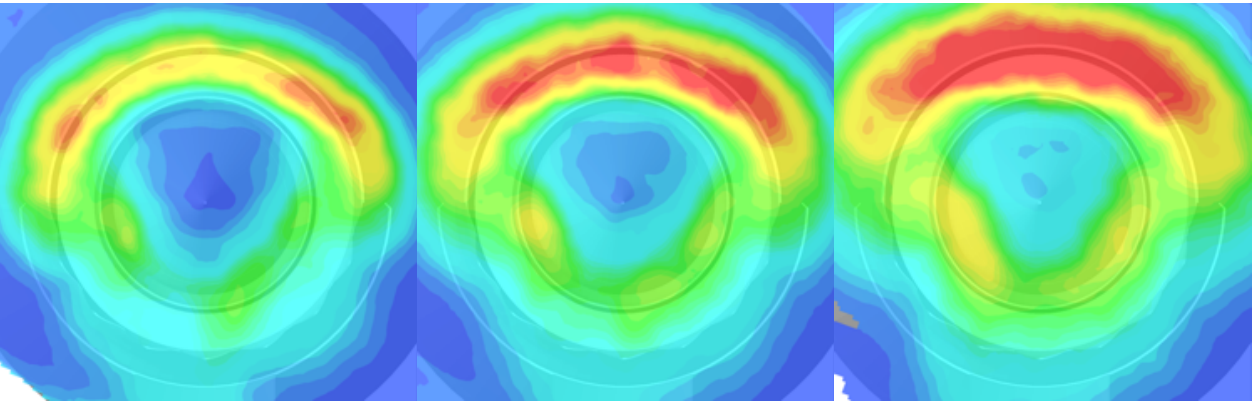

$500 \mathrm{~mm}$

$650 \mathrm{~mm}$

$850 \mathrm{~mm}$

Figure 21. Turbulent kinetic energy at $x=500,650,850 \mathrm{~mm}$ for the (a) $040 \mathrm{~B}$, (b) $040 \mathrm{~T}$ configurations at NPRp=2.0.

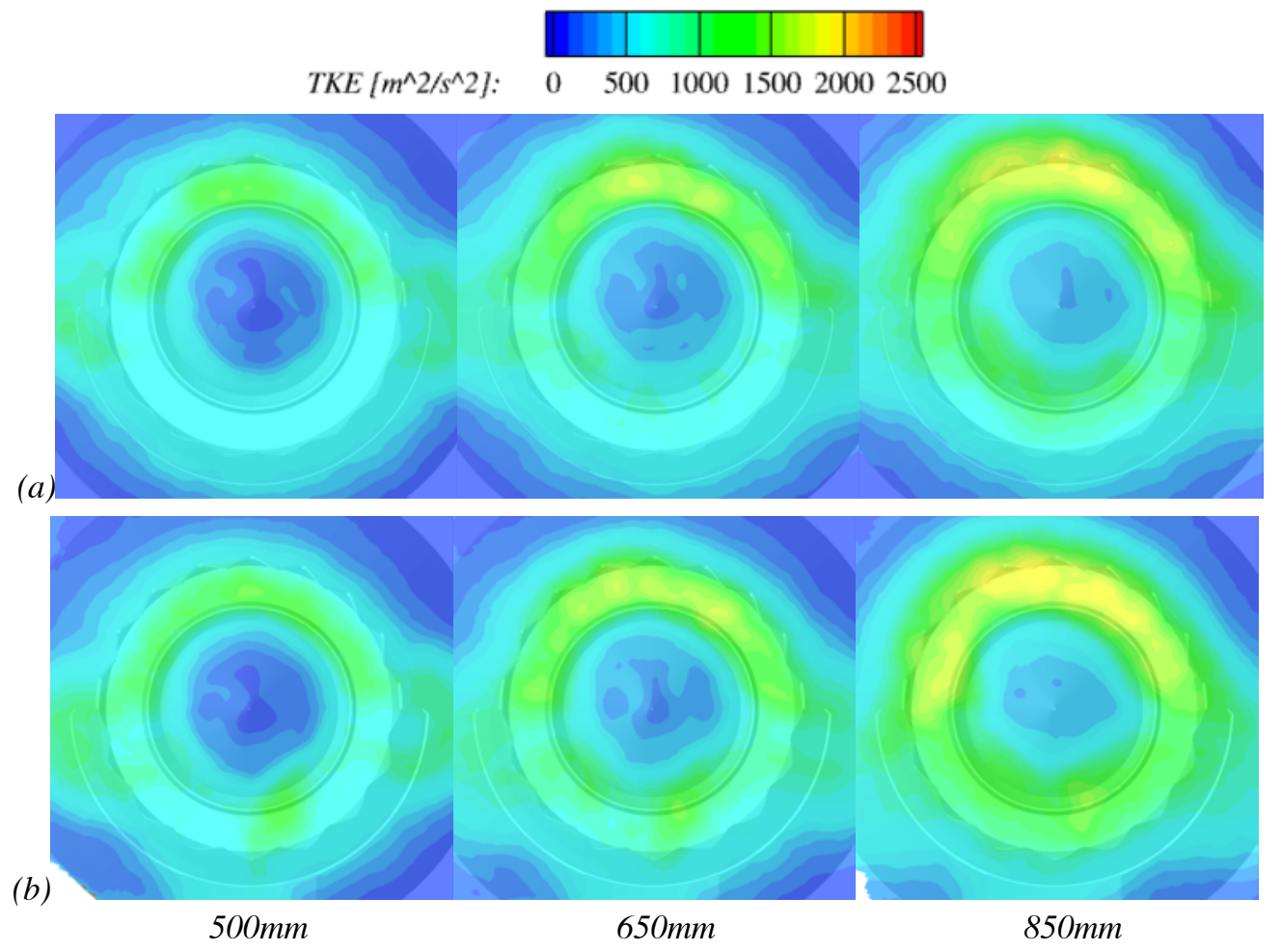

Figure 22. Turbulent kinetic energy at $x=500,650,850 \mathrm{~mm}$ for the (a) $240 \mathrm{~B}$, (b) $240 \mathrm{~T}$ configurations at NPRp=2.0. 


\section{Summary}

A model-scale exhaust system was tested to validate low-noise concepts and noise prediction methods. The tests involved far-field acoustics, translating phased array, and particle image velocimetry; this report covers the particle image velocimetry measurements. Flow measurements were made on an inverted-velocity-profile (IVP) nozzle, with an inner cold stream, a hot primary stream, and a half-annulus tertiary stream. Far-field and phased array measurements are being reported in companion papers. Flow measurements were made of the baseline configuration, and configurations with chevrons and planforms to simulate installation of the nozzle on an aircraft. Chevrons were added to the primary stream, with separate sets of chevrons on the half between primary and flight stream, and on the half between primary and tertiary streams. Chevrons with two different penetrations were used on each set to judge the impact of chevron penetration. For the baseline nozzle, two planforms of similar length but different standoffs were tested. For the chevron nozzles, the planform with higher standoff was tested on all the chevron nozzles to explore the impact of installation on the flow field.

For the baseline IVP nozzle, the main shear layer was between the primary stream and the flight stream. The inner shear layer between primary and inner flow quickly mixed, and no substantial TKE resulted from this, at least downstream of the nozzle plug. The shear layer between the tertiary and primary streams also mixed out very quickly and no turbulence was measured that was directly from this shear layer. The tertiary stream did reduce the gradient between the primary and flight streams, producing a slight asymmetry in the $T K E$ that was largely gone by the end of the potential core.

Flows from three engine cycle points were measured for the baseline IVP nozzle, differing in the primary stream velocity in increments of $10 \%$. Normalizing the $T K E$ by the difference in fully mixed and flight stream velocities, e.g. $T K E /\left(U_{m i x}-U_{\infty}\right)^{2}$, the normalized $T K E$ was found to peak at 0.022 , comparable to the value found for single-stream jets. When the directional components of the TKE were explored, it was found that the axial turbulence accounted for roughly half the TKE. This is again in keeping with findings in single-stream jets.

The flow phenomena produced by the chevrons were as expected. Chevrons caused strong mixing near the nozzle, and decreased TKE farther downstream in the plume. The potential core was extended by the chevrons because they reduced the mixing downstream that completes the mixing between the primary and flight streams. Or, put another way, they break up the low-order azimuthal vertical structures that would otherwise cause the plume to flap and bring low-speed fluid across the jet centerline, terminating the potential core.

The two chevron designs had penetrations of $10^{\circ}$ and $16^{\circ}$ to the jet centerline. The shear layer on the side opposite the low-penetration chevrons was largely unaffected by them. The higher chevron penetration caused greater mixing, reducing the TKE on both sides of the jet plume.

When the same high-penetration chevron designs were deployed on the nozzle lip between the primary and tertiary streams, the impact was very different than when they were deployed on the side between primary and flight stream. Even with little initial shear, the primary-tertiary chevrons produced a significant reduction of TKE downstream and produced TKE similar to the low penetration design on the primary-flight lip. That the tertiary stream mixed with the flight stream to a strong degree before encountering the chevrons may have increased the shear felt by the primarytertiary chevrons. The combination of chevrons on both sides of the primary nozzle produced the greatest reduction in downstream TKE of all the chevrons, the effects of the chevrons being somewhat additive.

To simulate installation of the nozzles on the top deck of an aircraft, two planforms were installed on the rig. The installations featured a convex-soled external pylon extending from the nozzle lip to the end of the deck. The planforms had approximately the same length, but the standoffs (the distance from the jet centerline to the surface) were different. One standoff was very minimal relative to the planform length while the second was much larger. The jet plume appeared to attach to the pylon of the low-standoff planform, producing a significant distortion of the shear layer by the downstream end of the pylon. However, the impact on TKE levels was small. The shear layer of the plume did not attach to the pylon of the higher standoff planform. The jet plume had no significant differences with or without the high-standoff planform.

The high-standoff planform was used for testing installation effects on the chevron nozzles. In keeping with the findings for the baseline IVP nozzle, the impact of installation on the plumes of the chevron nozzles was minimal. There was some increase in the shear layer strength downstream of the pylon side of the plume. This might be expected by the increased shear due to the wake of the planform on that side. Otherwise, the plumes had the same overall statistics with or without the planform installed. 
Companion papers ${ }^{6-8}$ show far-field noise and phased array measurements of the configurations presented here, along with computational studies of the nozzle designs.

\section{Acknowledgements}

This work was supported by the Commercial Supersonic Technology Project of the Advanced Air Vehicles Program at NASA. The excellent data were made possible by a highly skilled team of engineers and technicians at NASA Glenn's Aero-Acoustic Propulsion Lab, including PIV engineers Dr. Randy Locke, and Gary Clayo. Their diligence and dedication is greatly appreciated.

\section{References}

${ }^{1}$ Bridges, J., "Aeroacoustic Validation of Installed Low Noise Propulsion for NASA's N+2 Supersonic Airliner," AIAA SciTech Forum 2018, American Institute of Aeronautics and Astronautics, 2018.

${ }^{2}$ Bridges, J., and Brown, C., "Parametric Testing of Chevrons on Single Flow Hot Jets," 10th AIAA/CEAS Aeroacoustics Conference, American Institute of Aeronautics and Astronautics, 2004. doi:10.2514/6.2004-2824.

${ }^{3}$ Zaman, K. B. M. Q., Bridges, J. E., and Huff, D. L., “Evolution from 'Tabs' to 'Chevron Technology' - A Review,” International Journal of Aeroacoustics, vol. 10, Oct. 2011, pp. 685-709. doi:10.1260/1475-472X.10.5-6.685.

${ }^{4}$ Saiyed, N. H., Mikkelsen, K. L., and Bridges, J. E., "Acoustics and Thrust of Quiet Separate-Flow High-BypassRatio Nozzles," AIAA Journal, vol. 41, 2003, pp. 372-378. doi:10.2514/2.1986.

${ }^{5}$ Morgenstern, J., Buonanno, M., Yao, J., Murugappan, M., Paliath, U., Cheung, L., Malcevic, I., Ramakrishnan, K., Pastouchenko, N., Wood, T., Martens, S., Viars, P., Tersmette, T., Lee, J., Simmons, R., Plybon, D., Alonso, J., Palacios, F., Lukaczyk, T., and Carrier, G., Advanced Concept Studies for Supersonic Commercial Transports Entering Service in the 2018-2020 Period Phase 2, NASA/CR-2016-218319, 2015. https://ntrs.nasa.gov/search.jsp?R=20150015837.

${ }^{6}$ Bridges, J., "Noise measurements of a low-noise top-mounted propulsion installation for a supersonic airliner," AIAA SciTech Forum 2019, American Institute of Aeronautics and Astronautics, 2019.

${ }^{7}$ Cluts, J. D., Bridges, J., and Podboy, G. G., "Translating Phased Array Measurements of Noise Source Locations of an Installed Jet," AIAA SciTech Forum 2019, American Institute of Aeronautics and Astronautics, 2019.

${ }^{8}$ Heberling, B. C., "Numerical Investigation of a Shielded Chevron Nozzle," AIAA SciTech 2019, American Institute of Aeronautics and Astronautics, 2019.

9 Bridges, J., Brown, C. A., and Seidel, J. A., "NASA's Pursuit of Low-Noise Propulsion for Low-Boom Commercial Supersonic Vehicles," 54th AIAA Aerospace Sciences Meeting, 2018.

${ }^{10}$ Bridges, J. E., "Simple Scaling Of Multi-Stream Jet Plumes For Aeroacoustic Modeling," 54th AIAA Aerospace Sciences Meeting, American Institute of Aeronautics and Astronautics, 2016. doi:10.2514/6.2016-1637.

${ }^{11}$ Bridges, J., and Wernet, M. P., The NASA Subsonic Jet Particle Image Velocimetry (PIV) Dataset, NASA/TM2011-023688, 2011. https://ntrs.nasa.gov/search.jsp?R=20110023688.

${ }^{12}$ Henderson, B. S., and Wernet, M., "Characterization of Three-Stream Jet Flow Fields," 54th AIAA Aerospace Sciences Meeting, American Institute of Aeronautics and Astronautics, 2016. doi:10.2514/6.2016-1636. 